\title{
Novel Pharmaceutical Cocrystals and Salts of Bumetanide
}

Suryanarayana Allu†, Geetha Bolla†, Srinu Tothadił, and Ashwini K. Nangia*†t

$\dagger$ School of Chemistry, University of Hyderabad, Prof. C. R. Rao Road, Gachibowli, Central University P.O, Hyderabad 500 046, India.

$\ddagger$ Materials Chemistry Division, CSIR-National Chemical Laboratory, Dr. Homi Bhabha Road, Pune 411 008, India.

\begin{tabular}{|c|l|c|}
\hline S. No. & \multicolumn{1}{|c|}{ Contents } & Page Numbers \\
\hline Table S1 & $\begin{array}{l}\text { Hydrogen bond table of BUM cocrystal/salts and salt- } \\
\text { cocrystals }\end{array}$ & S1 \\
\hline Section S1 & PXRD Comparison of BUM cocrystal/salts and salt-cocrystals & S4 \\
\hline Section S2 & $\begin{array}{l}\text { PXRD Overlay of experimental line pattern with calculated } \\
\text { profilefrom the X-ray crystal structure }\end{array}$ & S8 \\
\hline Section S3 & FT-IR of BUM cocrystal/salts and salt-cocrystals & S11 \\
\hline Section S4 & DSC of BUM cocrystal/salts and salt-cocrystals & S16 \\
\hline Section S5 & $\begin{array}{l}\text { PXRD analysis to determine crystal form phase stability at 24 } \\
\text { h (equilibrium solubility) and 8h (dissolution) in pH 7 buffer } \\
\text { media. }\end{array}$ & S20 \\
\hline Table S3 & $\begin{array}{l}\text { ORTEP Diagrams of BUM and its cocrystal/salts and salt- } \\
\text { cocrystals }\end{array}$ & S28 \\
\hline Figure S46 & UV absorption of the BUM & S29 \\
\hline Table S4 & Unsuccessful crystallizations & S29 \\
\hline
\end{tabular}

Table S1: Hydrogen bonds in BUM cocrystal/salts $(\mathrm{N}-\mathrm{H}, \mathrm{O}-\mathrm{H}$, and $\mathrm{C}-\mathrm{H}$ distances are neutronnormalized)

\begin{tabular}{|c|c|c|c|c|c|}
\hline Name & $\mathrm{D}-\mathrm{H} \cdots \mathrm{A}$ & $\mathrm{D} \cdots \mathrm{A}(\AA)$ & $\begin{array}{c}\mathrm{H} \cdots \mathrm{A} \\
(\AA)\end{array}$ & $\begin{array}{c}\mathrm{D}-\mathrm{H} \cdots \mathrm{A} \\
\left({ }^{\circ}\right)\end{array}$ & symmetry code \\
\hline \multirow{4}{*}{$\begin{array}{c}\text { BUM-UREA } \\
(\mathbf{1 : 1 )}\end{array}$} & $\mathrm{N} 1-\mathrm{H} 1 \mathrm{~A} \cdots \mathrm{O} 3$ & $2.767(4)$ & $2.44(3)$ & $109(3)$ & $\mathrm{x}, \mathrm{y}, \mathrm{z}$ \\
\cline { 2 - 6 } & $\mathrm{N} 2-\mathrm{H} 2 \mathrm{~A} \cdots \mathrm{O} 1$ & $3.145(4)$ & $2.49(4)$ & $137(3)$ & $1+\mathrm{x}, \mathrm{y}, \mathrm{z}$ \\
\cline { 2 - 6 } & $\mathrm{N} 2-\mathrm{H} 2 \mathrm{~B} \cdots \mathrm{O} 6$ & $2.984(4)$ & $2.18(4)$ & $167(3)$ & $\mathrm{x}, \mathrm{y}, 1+\mathrm{z}$ \\
\cline { 2 - 6 } & $\mathrm{N} 3-\mathrm{H} 3 \mathrm{~A} \cdots \mathrm{O} 5$ & $3.073(4)$ & $2.33(4)$ & $151(4)$ & $\mathrm{x}, \mathrm{y}, \mathrm{z}$ \\
\cline { 2 - 6 } & $\mathrm{N} 3-\mathrm{H} 3 \mathrm{~B} \cdots \mathrm{O} 4$ & $2.985(4)$ & $2.42(4)$ & $129(4)$ & $\begin{array}{l}1+\mathrm{x}, 1 / 2-\mathrm{y},- \\
1 / 2+\mathrm{z}\end{array}$ \\
\hline
\end{tabular}




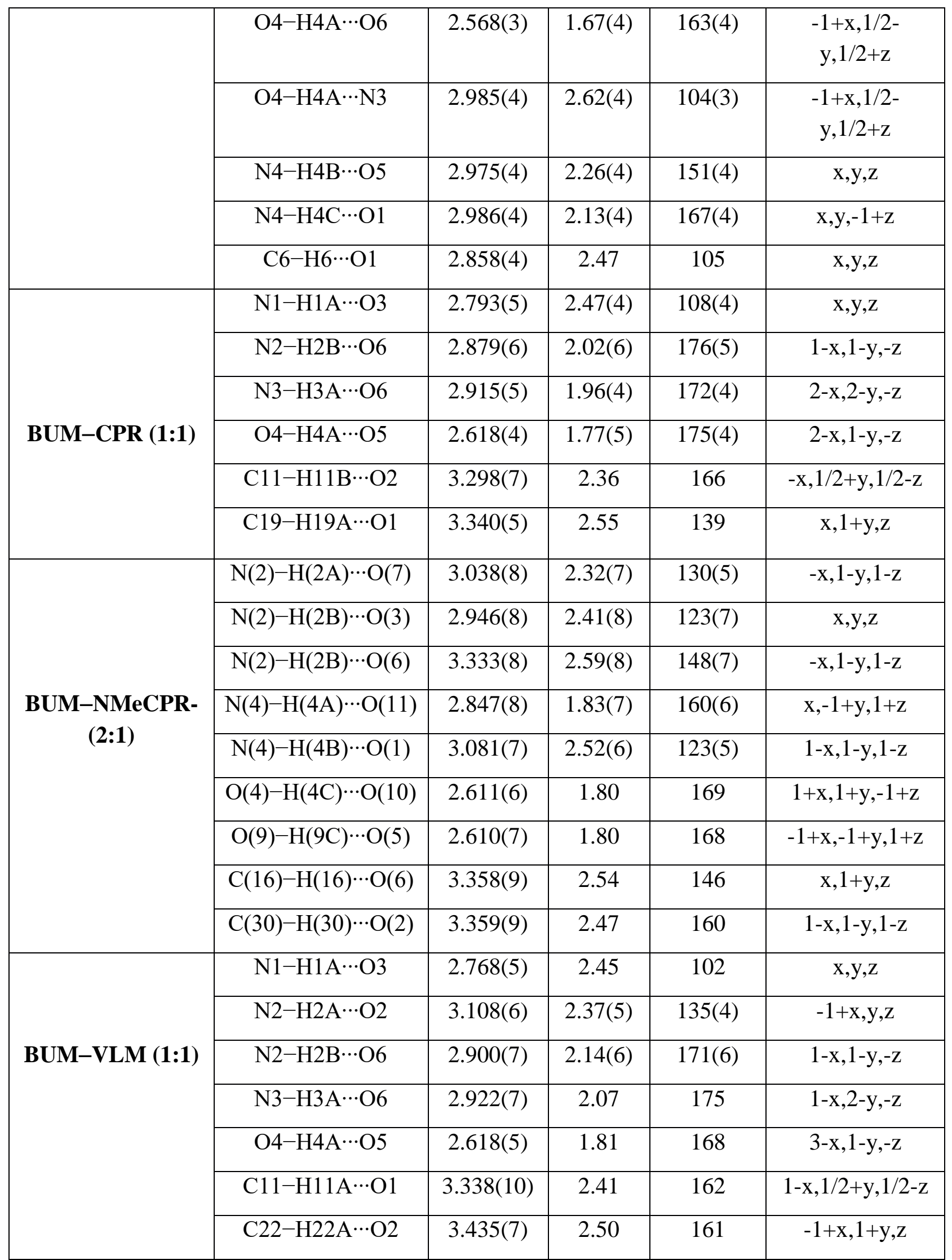




\begin{tabular}{|c|c|c|c|c|c|}
\hline \multirow{8}{*}{ BUM-4AP $(1: 1)$} & $\mathrm{N} 1-\mathrm{H} 1 \mathrm{~A} \cdots \mathrm{O} 3$ & $2.744(3)$ & $2.40(3)$ & $108(3)$ & $\mathrm{x}, \mathrm{y}, \mathrm{z}$ \\
\hline & $\mathrm{N} 2-\mathrm{H} 2 \mathrm{~A} \cdots \mathrm{O} 5$ & $3.007(3)$ & $2.14(3)$ & $169(2)$ & $\mathrm{x}, 1 / 2-\mathrm{y}, 1 / 2+\mathrm{z}$ \\
\hline & $\mathrm{N} 2-\mathrm{H} 2 \mathrm{~B} \cdots \mathrm{O} 4$ & $2.870(3)$ & $1.93(4)$ & $168(3)$ & 2-x,1-y,1-z \\
\hline & $\mathrm{N} 3-\mathrm{H} 3 \mathrm{~A} \cdots \mathrm{O} 5$ & $2.668(3)$ & $1.77(4)$ & $172(3)$ & $1-x, 1-y,-z$ \\
\hline & $\mathrm{N} 4-\mathrm{H} 4 \mathrm{~A} \cdots \mathrm{O} 4$ & $2.842(4)$ & $1.91(4)$ & 167(4) & $1-x,-1 / 2+y, 1 / 2-z$ \\
\hline & $\mathrm{N} 4-\mathrm{H} 4 \mathrm{~B} \cdots \mathrm{O} 1$ & $3.307(4)$ & $2.58(3)$ & $162(4)$ & $1-x, 1-y, 1-z$ \\
\hline & $\mathrm{C} 8-\mathrm{H} 8 \mathrm{~B} \cdots \mathrm{O} 2$ & $3.273(5)$ & 2.47 & 141 & $\mathrm{x}, 1 / 2-\mathrm{y},-1 / 2+\mathrm{z}$ \\
\hline & $\mathrm{C} 14-\mathrm{H} 14 \cdots \mathrm{O} 2$ & $3.404(4)$ & 2.53 & 157 & $1-x, 1-y, 1-z$ \\
\hline \multirow{14}{*}{$\begin{array}{c}\text { BUM-PIP- } \\
(2: 2: 3)\end{array}$} & $\mathrm{N} 2-\mathrm{H} 2 \mathrm{~A} \cdots \mathrm{O} 1$ & $3.182(6)$ & $2.59(4)$ & $132(4)$ & $1+\mathrm{x}, \mathrm{y}, \mathrm{z}$ \\
\hline & $\mathrm{N} 2-\mathrm{H} 2 \mathrm{~B} \cdots \mathrm{O} 9$ & $2.837(7)$ & $2.04(7)$ & 177(6) & $-x,-y, 1-z$ \\
\hline & N4-H4A№11 & $2.890(11)$ & $1.84(9)$ & 167(7) & $\mathrm{x}, \mathrm{y}, \mathrm{z}$ \\
\hline & 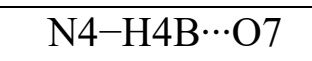 & $3.150(6)$ & $2.47(6)$ & $139(4)$ & $1+\mathrm{x}, \mathrm{y}, \mathrm{z}$ \\
\hline & N5-H5A $\cdots \mathrm{O} 4$ & $2.756(5)$ & 1.87 & 172 & $1+\mathrm{x}, \mathrm{y}, \mathrm{z}$ \\
\hline & N5-H5A $\cdots$ O5 & $3.154(5)$ & 2.50 & 130 & $1+\mathrm{x}, \mathrm{y}, \mathrm{z}$ \\
\hline & 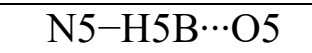 & $2.701(5)$ & 1.82 & 173 & $\mathrm{x}, \mathrm{y}, \mathrm{z}$ \\
\hline & N6-H6A $\cdots$ O9 & $2.748(6)$ & $1.85(5)$ & $165(5)$ & $\mathrm{x}, \mathrm{y}, \mathrm{z}$ \\
\hline & N6-H6B $\cdots \mathrm{O} 10$ & $2.674(6)$ & $1.80(4)$ & $157(4)$ & $1+\mathrm{x}, \mathrm{y}, \mathrm{z}$ \\
\hline & $\mathrm{O} 12-\mathrm{H} 12 \mathrm{D} \cdots \mathrm{O} 13$ & $2.761(11)$ & $2.21(10)$ & $117(8)$ & $-1+\mathrm{x}, \mathrm{y}, \mathrm{z}$ \\
\hline & $\mathrm{O} 13-\mathrm{H} 13 \mathrm{D} \cdots \mathrm{O} 12$ & $2.761(11)$ & $1.77(10)$ & $165(12)$ & $1+\mathrm{x}, \mathrm{y}, \mathrm{z}$ \\
\hline & 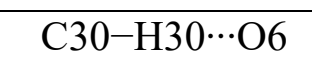 & $3.477(7)$ & 2.56 & 171 & $1+\mathrm{x}, \mathrm{y}, \mathrm{z}$ \\
\hline & $\mathrm{C} 36-\mathrm{H} 36 \mathrm{~A} \cdots \mathrm{O} 7$ & $3.236(5)$ & 2.56 & 127 & $-x,-y, 1-z$ \\
\hline & $\mathrm{C} 38-\mathrm{H} 38 \mathrm{~B} \cdots \mathrm{O} 1$ & $3.299(7)$ & 2.54 & 136 & $-\mathrm{x}, 1-\mathrm{y}, 1-\mathrm{z}$ \\
\hline \multirow{4}{*}{$\begin{array}{c}\text { BUM-5FCYT } \\
(2: 1)\end{array}$} & $\mathrm{N} 2-\mathrm{H} 2 \mathrm{~A} \cdots \mathrm{O} 11$ & $2.944(5)$ & 2.14 & 155 & $1+\mathrm{x}, \mathrm{y}, \mathrm{z}$ \\
\hline & $\mathrm{N} 4-\mathrm{H} 4 \mathrm{~B} \cdots \mathrm{O} 9$ & $2.928(5)$ & 2.21 & 142 & $1-x,-y, 1-z$ \\
\hline & N5-H5A $\cdots$ O10 & $2.761(4)$ & 1.90 & 178 & $-1+x, y, z$ \\
\hline & 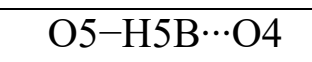 & $2.612(5)$ & 1.80 & 172 & $-x, 1-y,-z$ \\
\hline
\end{tabular}




\begin{tabular}{|c|c|c|c|l|c|}
\hline \multirow{4}{*}{} & $\mathrm{N} 6-\mathrm{H} 6 \cdots \mathrm{O} 11$ & $2.809(5)$ & 1.96 & 170 & $-\mathrm{x}, 1-\mathrm{y}, 1-\mathrm{z}$ \\
\cline { 2 - 6 } & $\mathrm{N} 7-\mathrm{H} 7 \mathrm{~A} \cdots \mathrm{O} 9$ & $2.652(4)$ & 1.80 & 173 & $-1+\mathrm{x}, \mathrm{y}, \mathrm{z}$ \\
\cline { 2 - 6 } & $\mathrm{N} 7-\mathrm{H} 7 \mathrm{~B} \cdots \mathrm{O} 6$ & $2.888(5)$ & 2.14 & 146 & $1-\mathrm{x},-\mathrm{y}, 1-\mathrm{z}$ \\
\cline { 2 - 6 } & $\mathrm{C} 14-\mathrm{H} 14 \cdots \mathrm{F} 1$ & $3.348(6)$ & 2.48 & 156 & $2-\mathrm{x}, 1-\mathrm{y}, 1-\mathrm{z}$ \\
\cline { 2 - 6 } & $\mathrm{C} 30-\mathrm{H} 30 \cdots \mathrm{O} 7$ & $3.523(7)$ & 2.59 & 177 & $-1+\mathrm{x}, \mathrm{y}, \mathrm{z}$ \\
\cline { 2 - 6 } & $\mathrm{C} 38-\mathrm{H} 38 \cdots \mathrm{O} 2$ & $3.112(5)$ & 2.31 & 144 & $1-\mathrm{x}, 1-\mathrm{y}, 1-\mathrm{z}$ \\
\hline
\end{tabular}

Section S1: PXRD Comparison of BUM cocrystal/salts and salt-cocrystals with that of the starting components

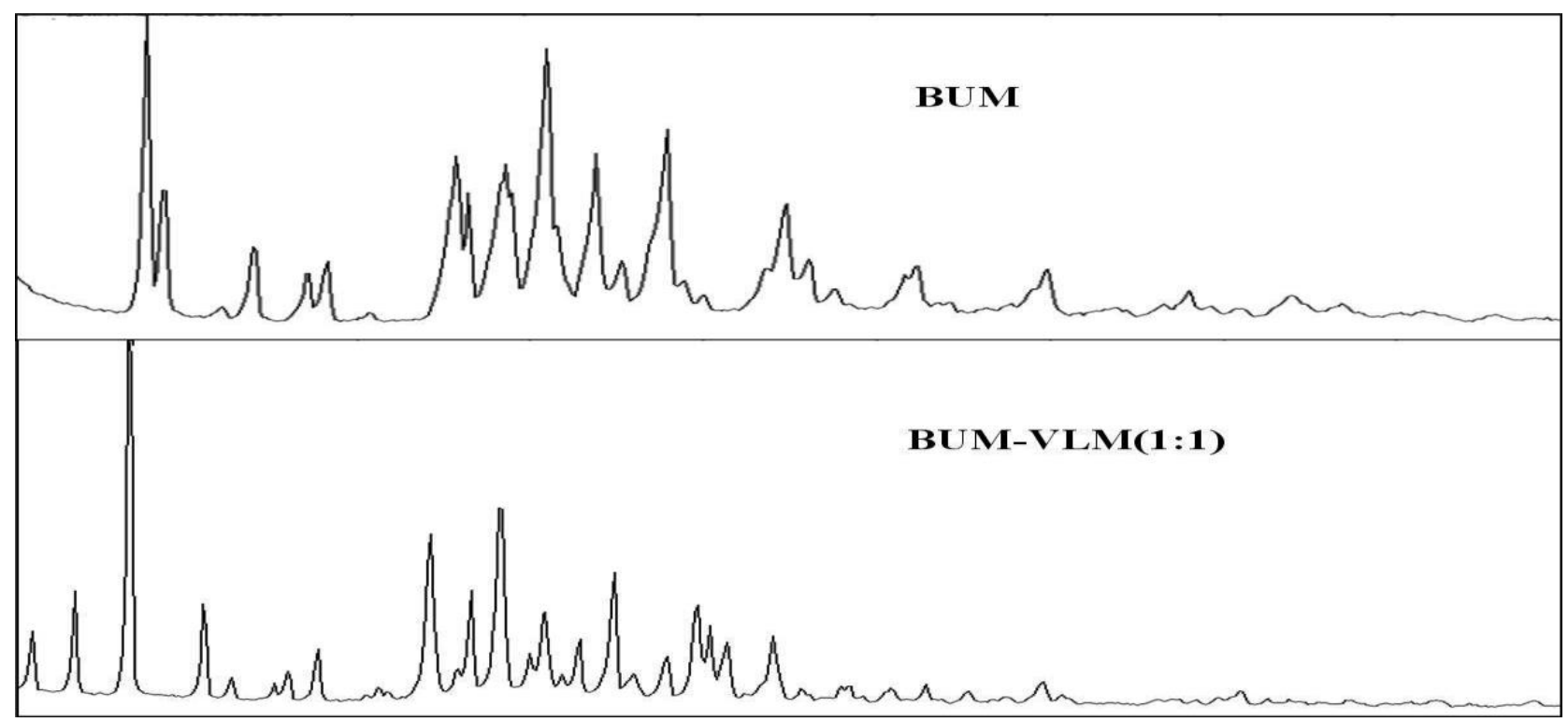

Figure S1: PXRD comparison of BUM-VLM (1:1) cocrystal. 


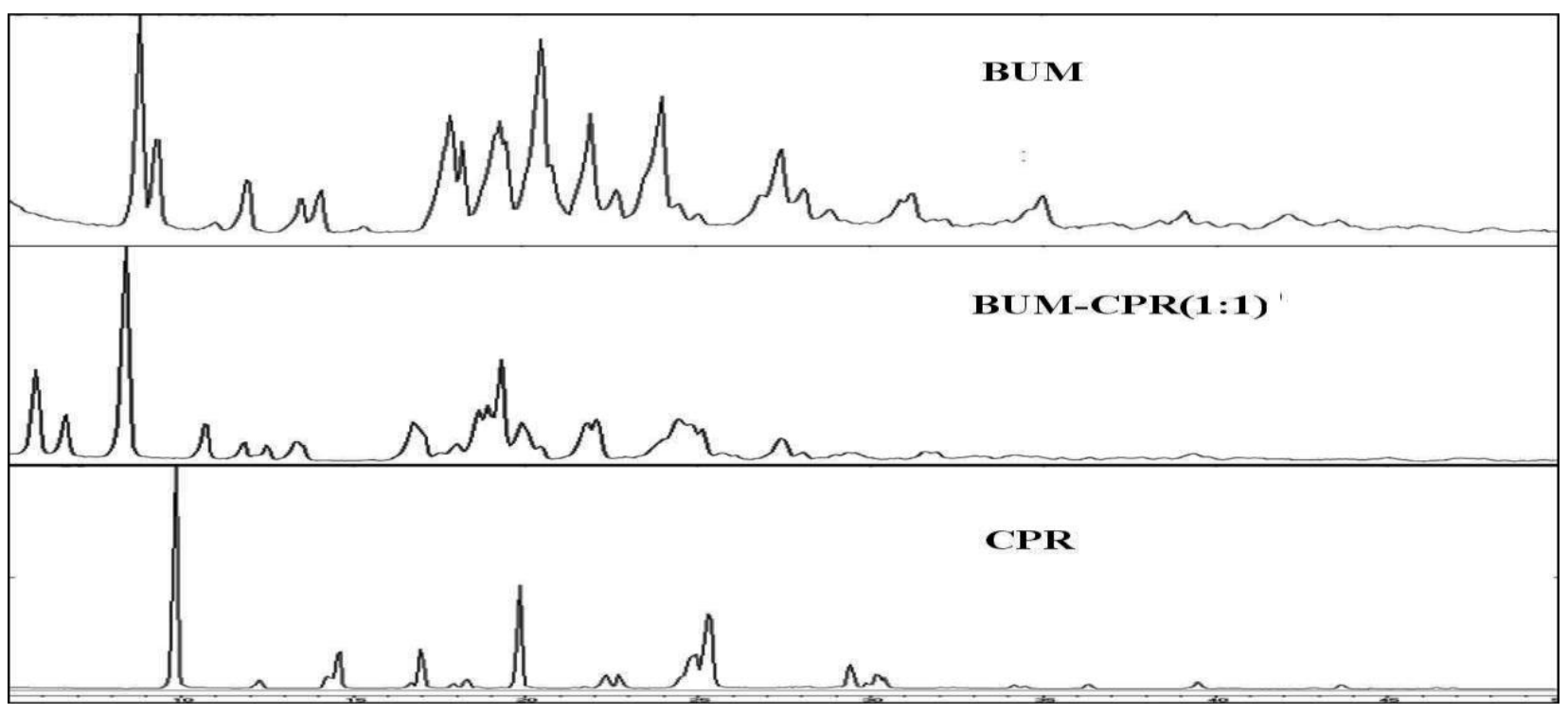

Figure S2: PXRD comparison of BUM-CPR (1:1) cocrystal.

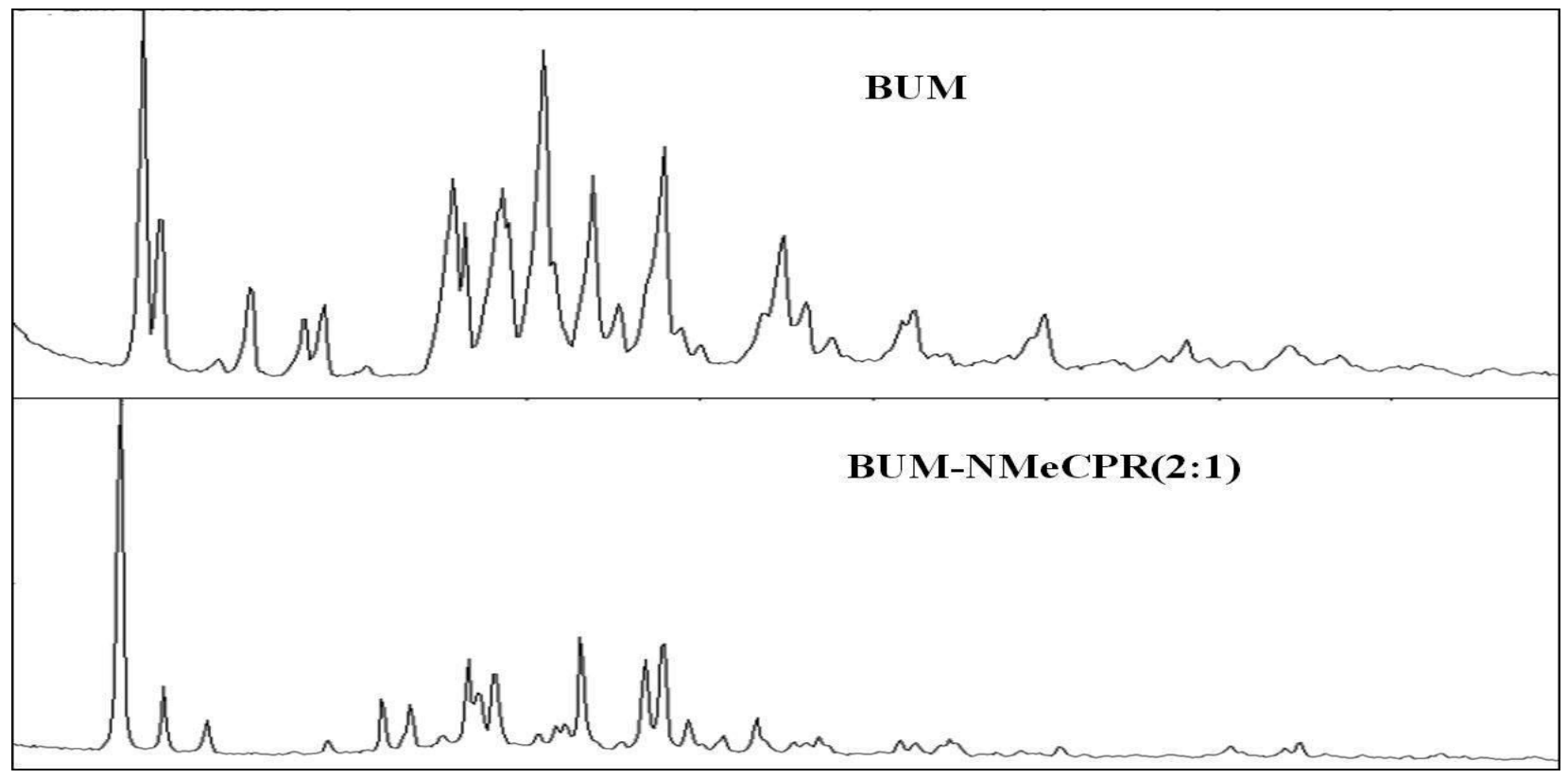

Figure S3: PXRD comparison of BUM-NMeCPR (2:1) cocrystal. 


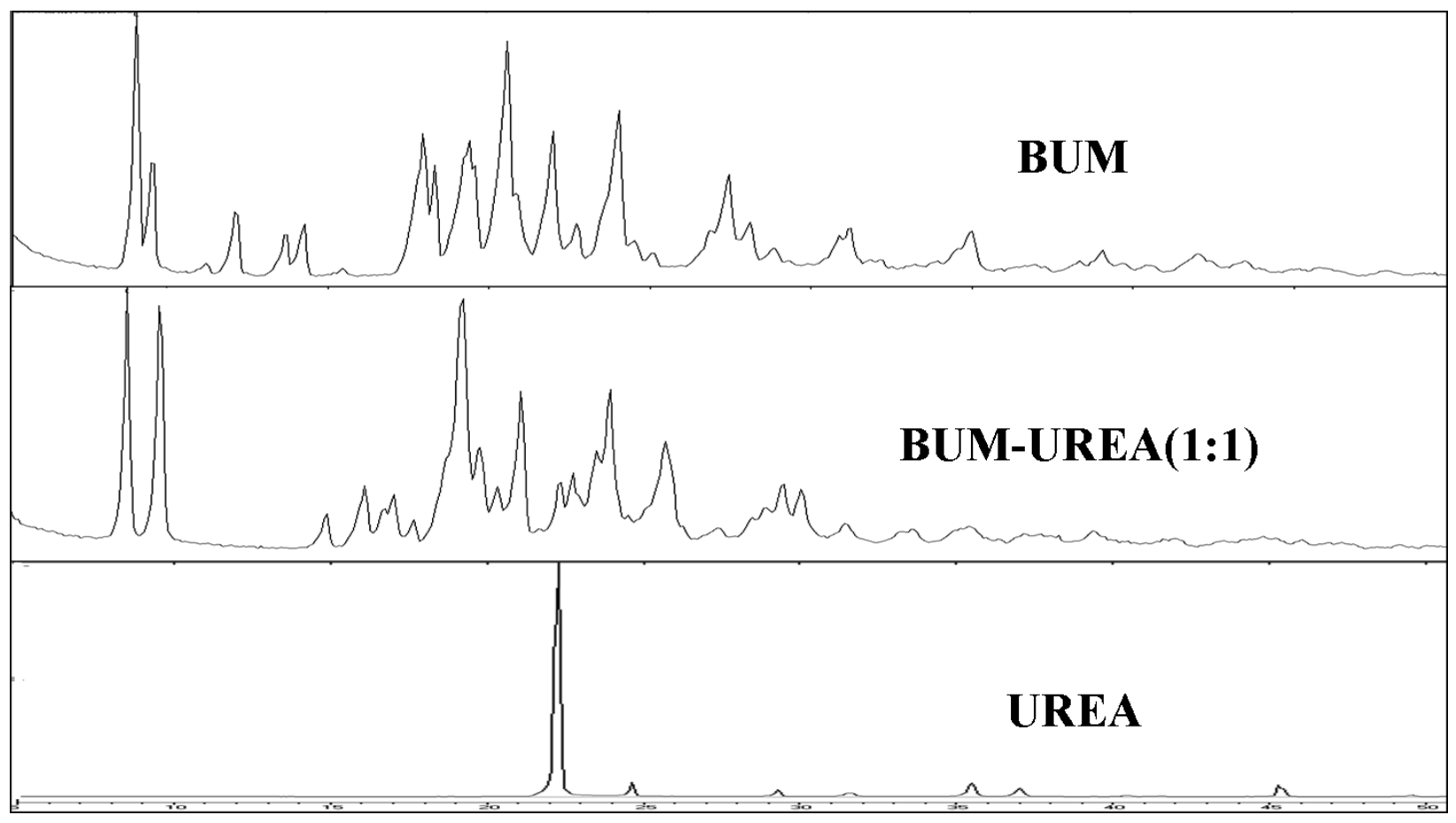

Figure S4: PXRD comparison of BUM-UREA (1:1) cocrystal.

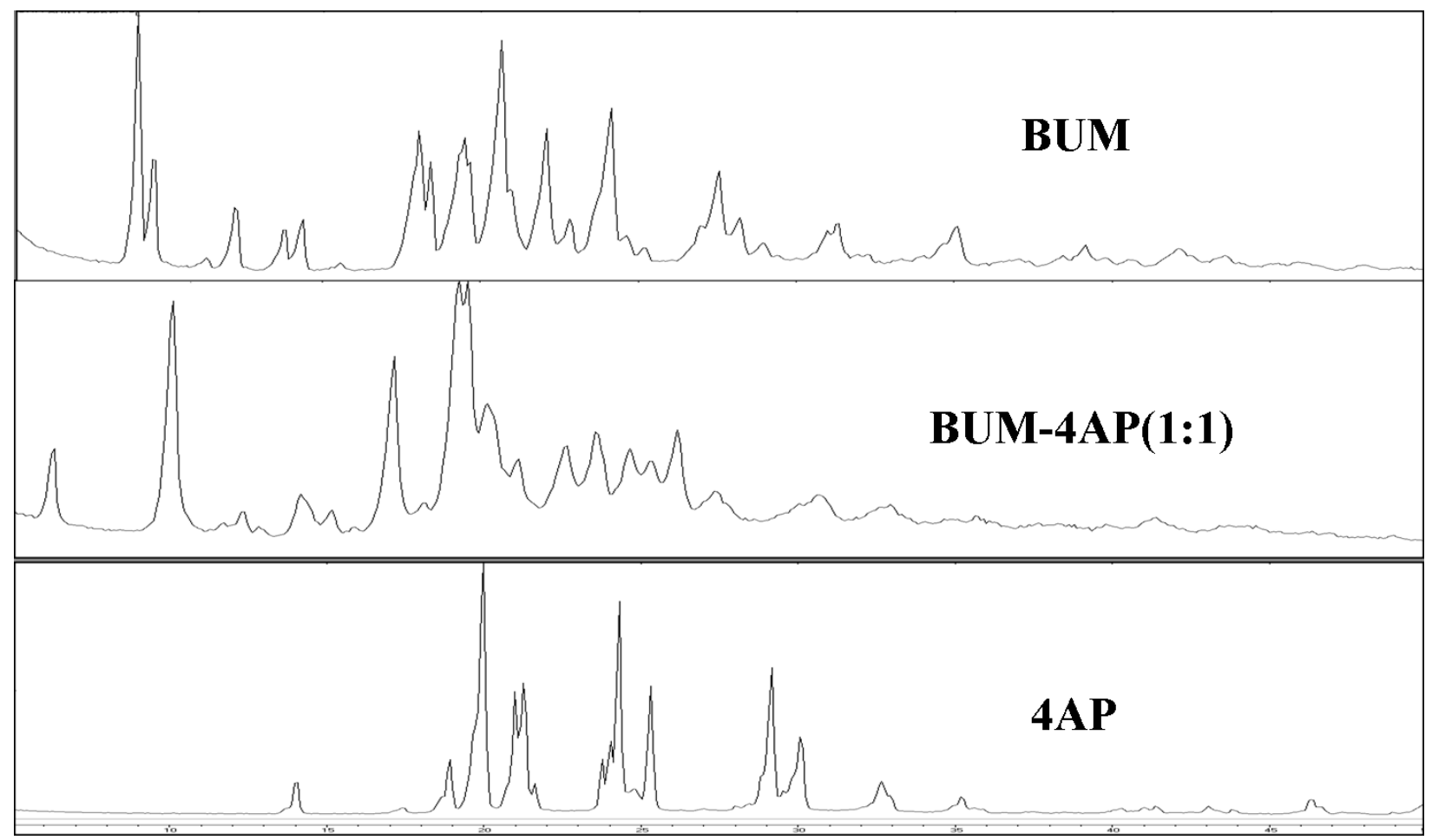

Figure S5: PXRD comparison of BUM-4AP (1:1) salt. 


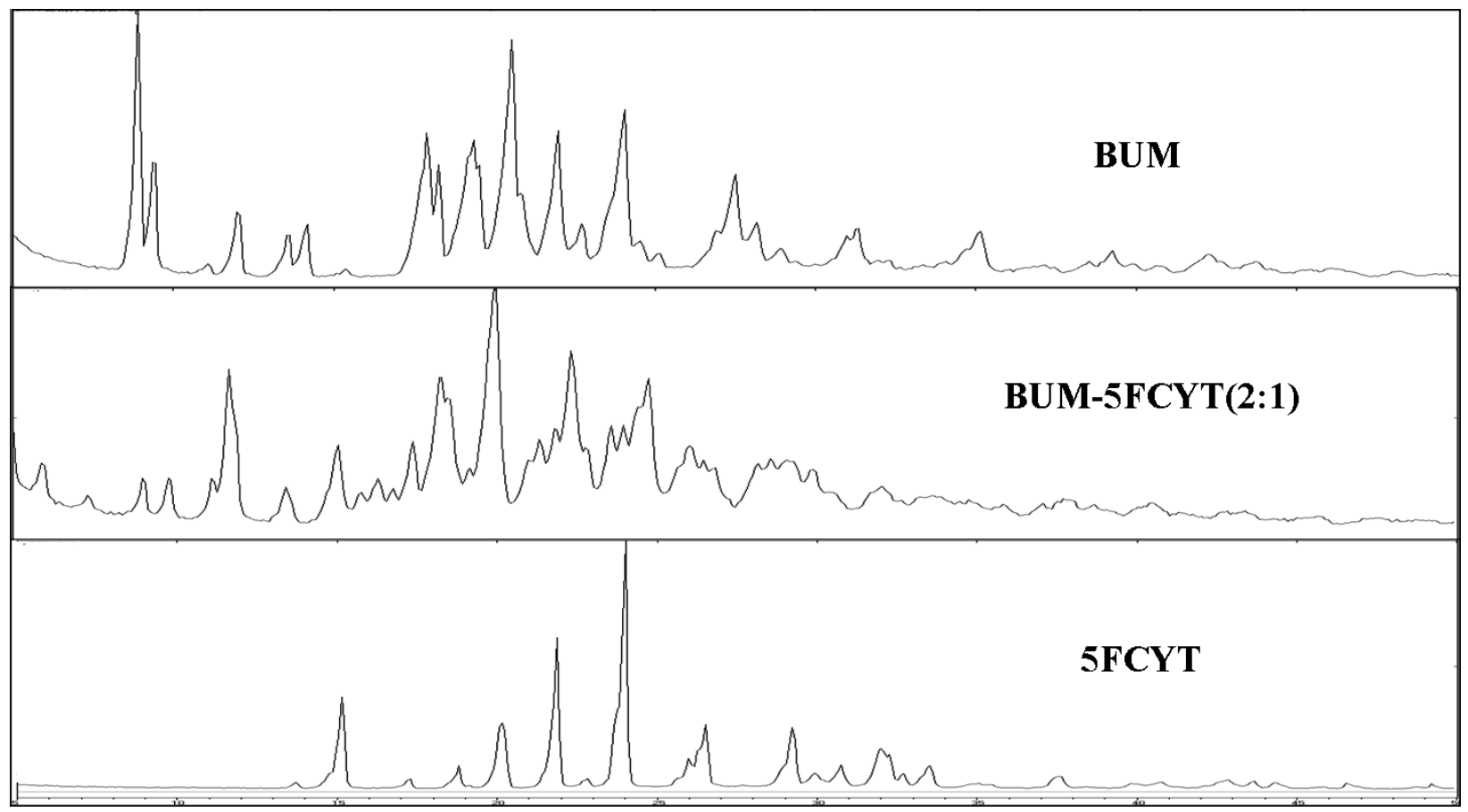

Figure S6: PXRD comparison of BUM-5FCYT (2:1) cocrystal salt.

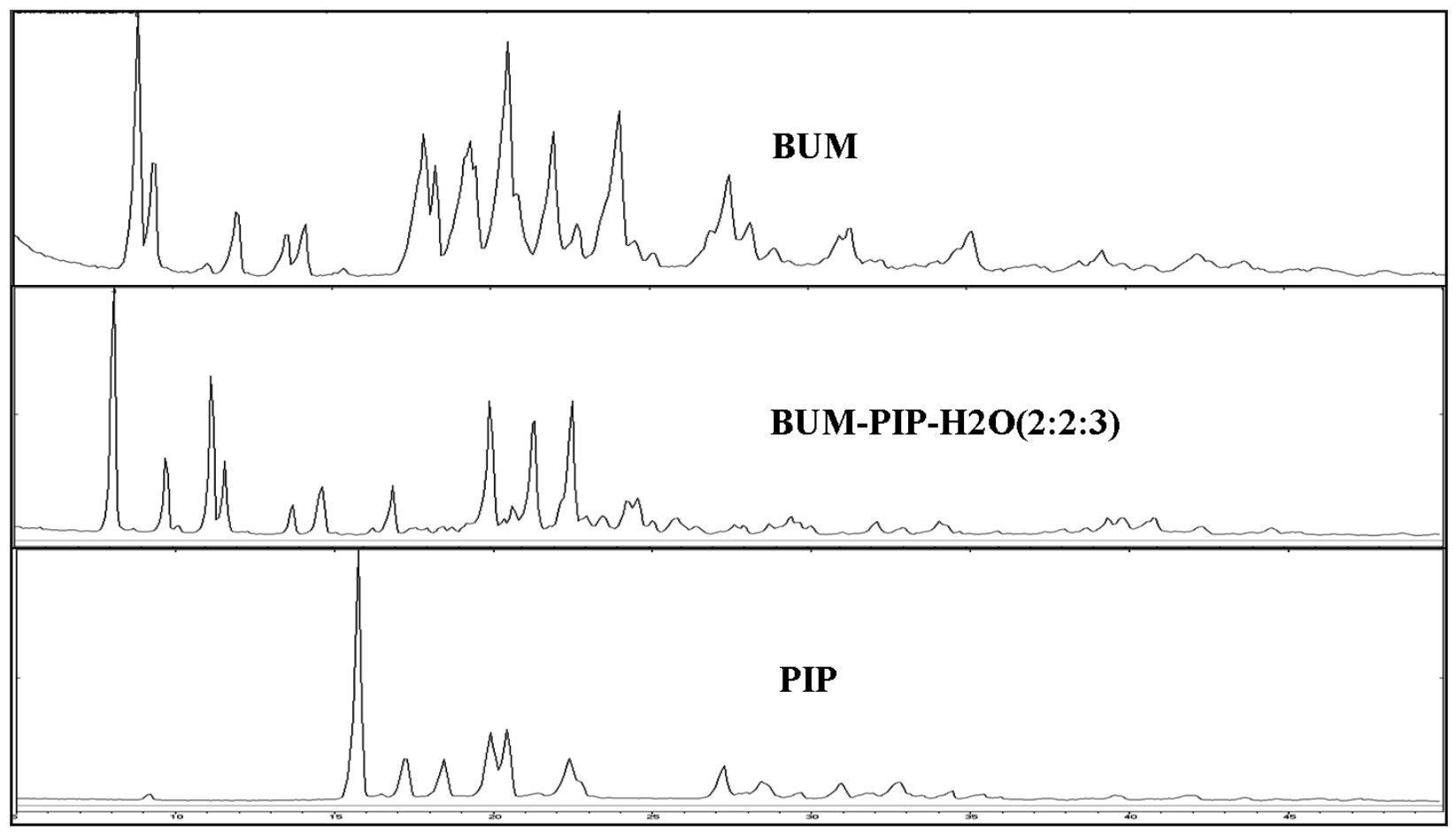

Figure S7: PXRD comparison of $\mathrm{BUM}-\mathrm{PIP}-\mathrm{H}_{2} \mathrm{O}(2: 2: 3)$ salt-hydrate. 
Section S2: PXRD Overlay of experimental line pattern with calculated profile from the $X$ ray crystal structure

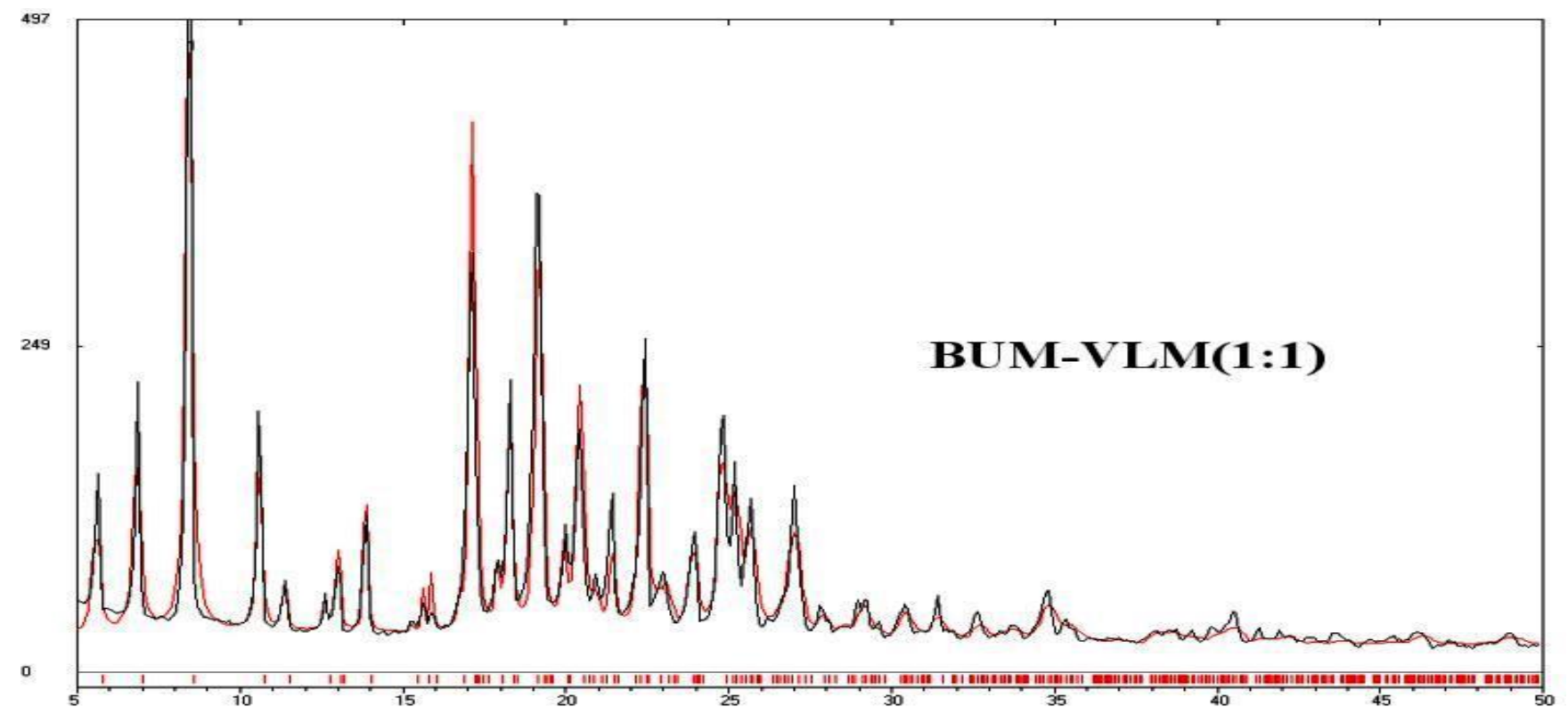

Figure S8: Overlay of BUM-VLM (1:1) cocrystal of powder pattern with the calculated line pattern of the crystal structure.

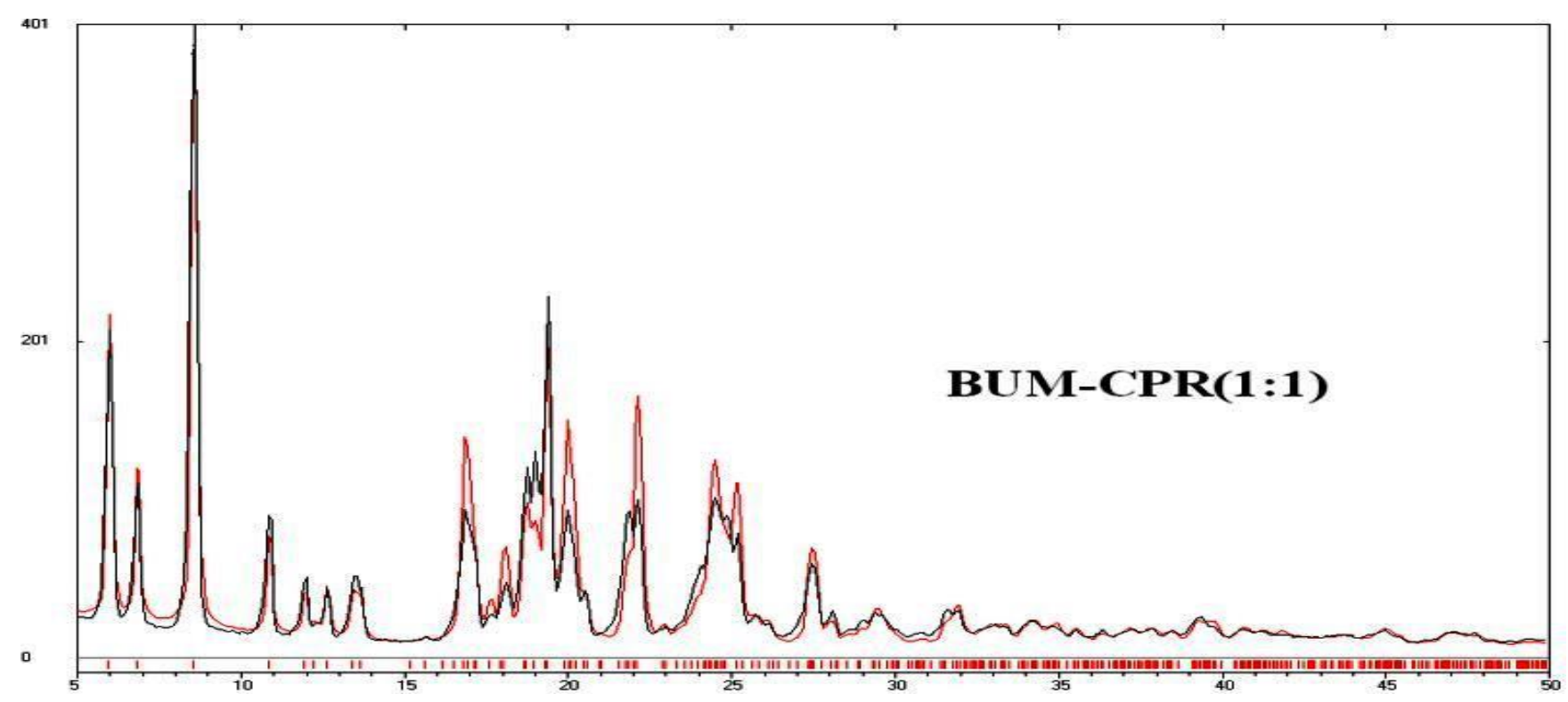

Figure S9: Overlay of BUM-CPR (1:1) cocrystal powder XRD pattern with the calculated line pattern of the crystal structure. 


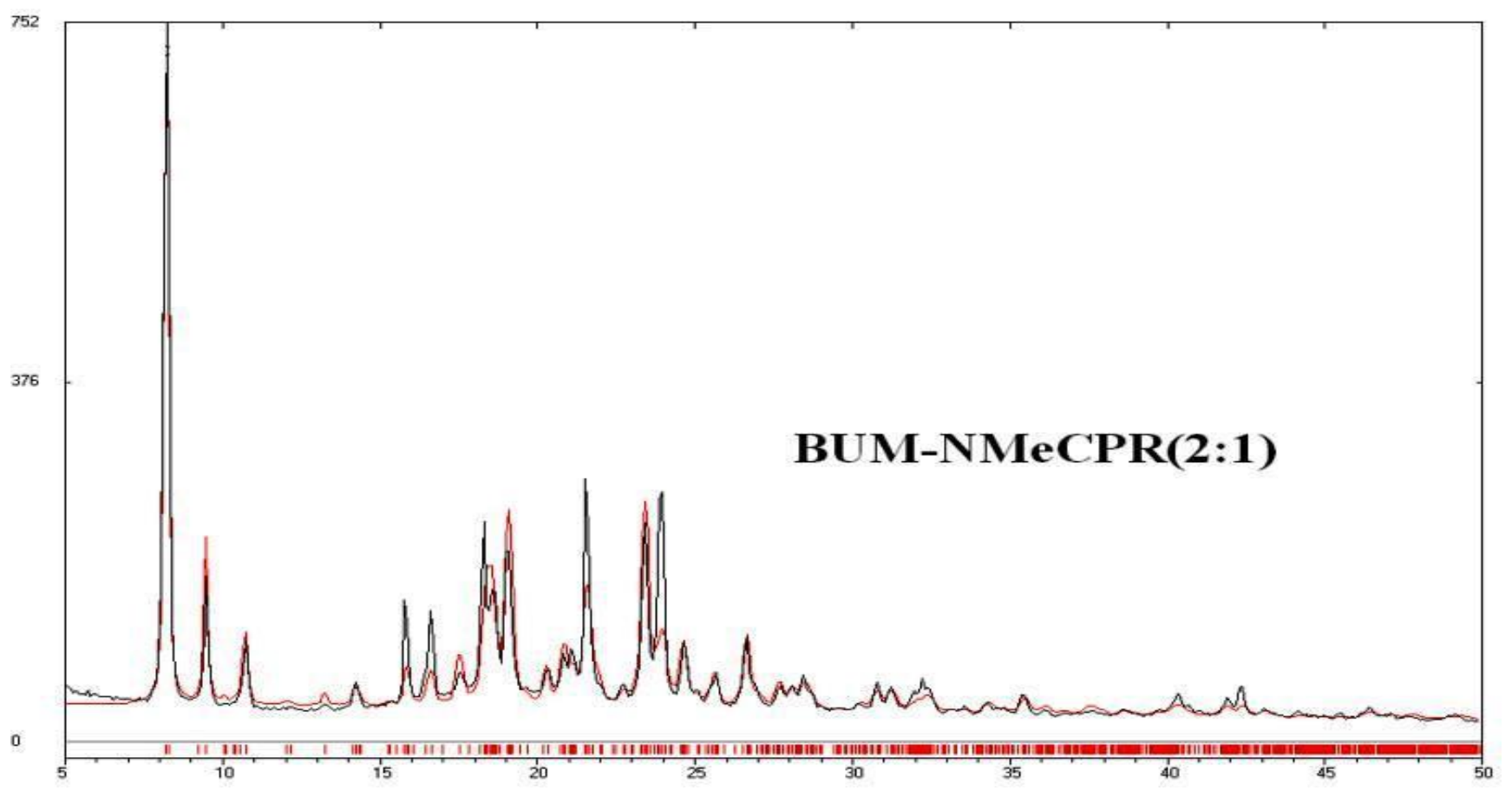

Figure S10: Overlay of BUM-NMeCPR (2:1) cocrystal of powder pattern with calculated line pattern of the crystal structure.

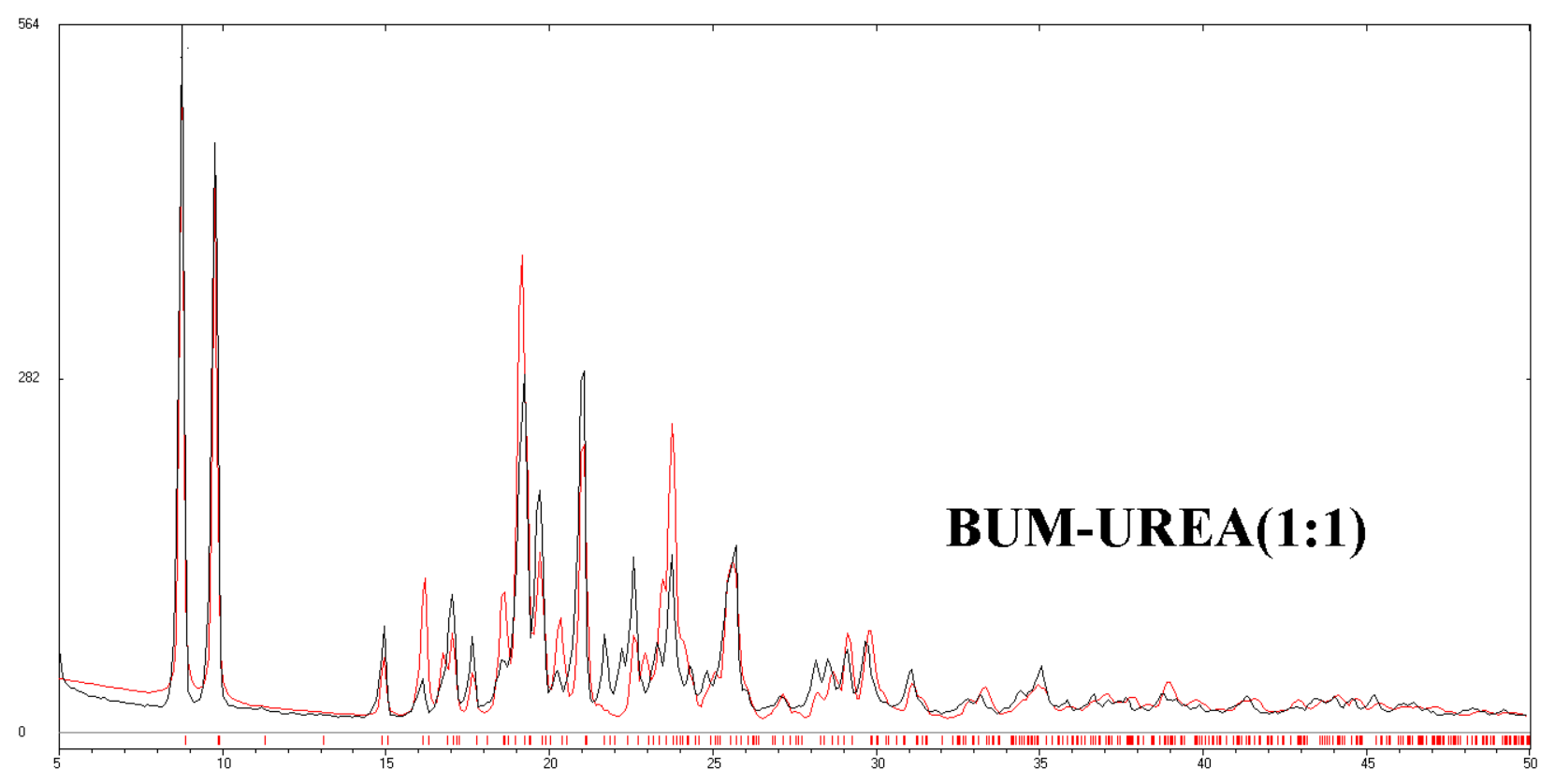

Figure S11: overlay of BUM-UREA (1:1) cocrystal of powder pattern with calculated line pattern of the crystal structure. 


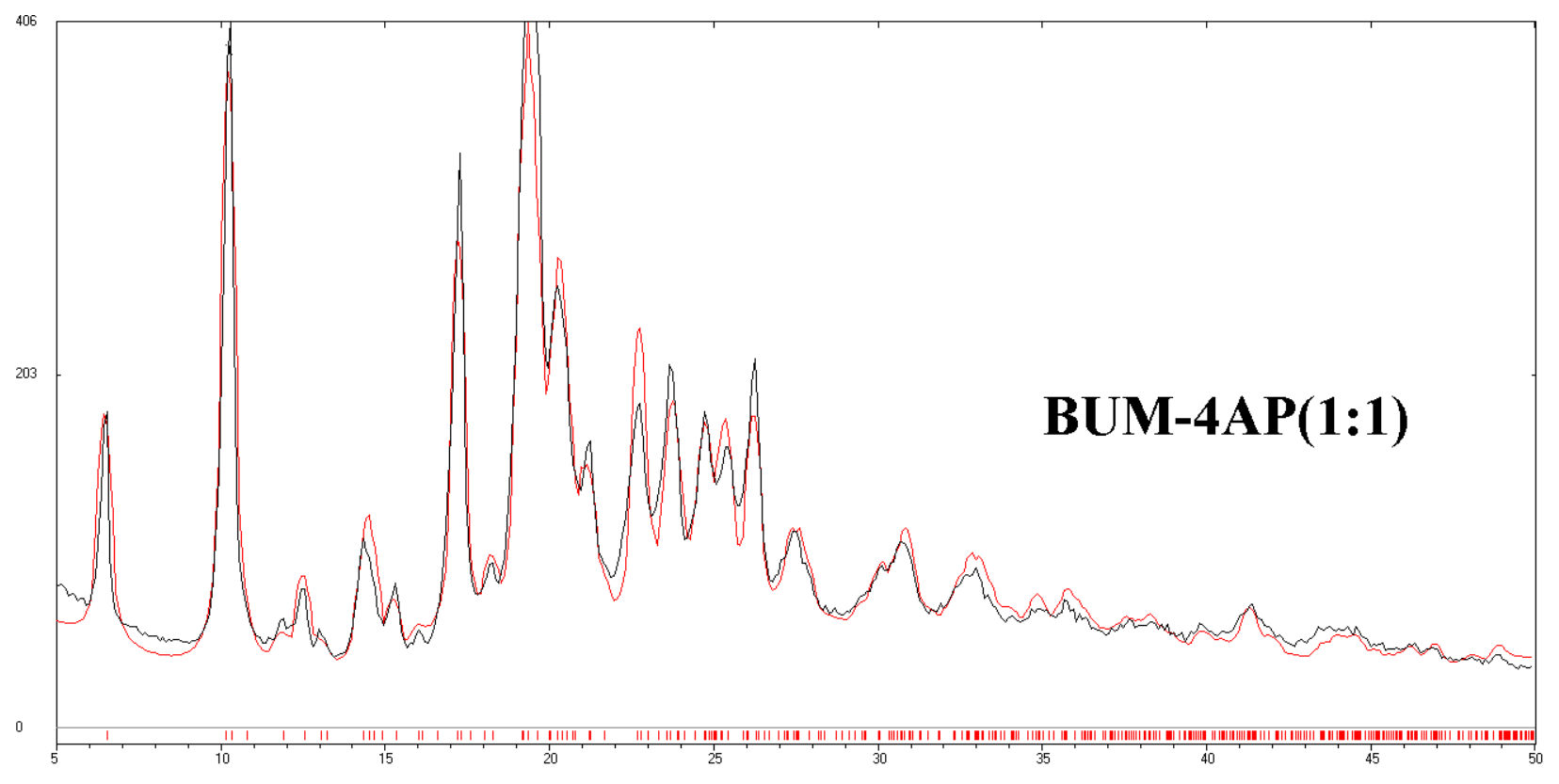

Figure S12: Overlay of BUM-4AP (1:1) Salt of powder pattern with calculated line pattern of the crystal structure.

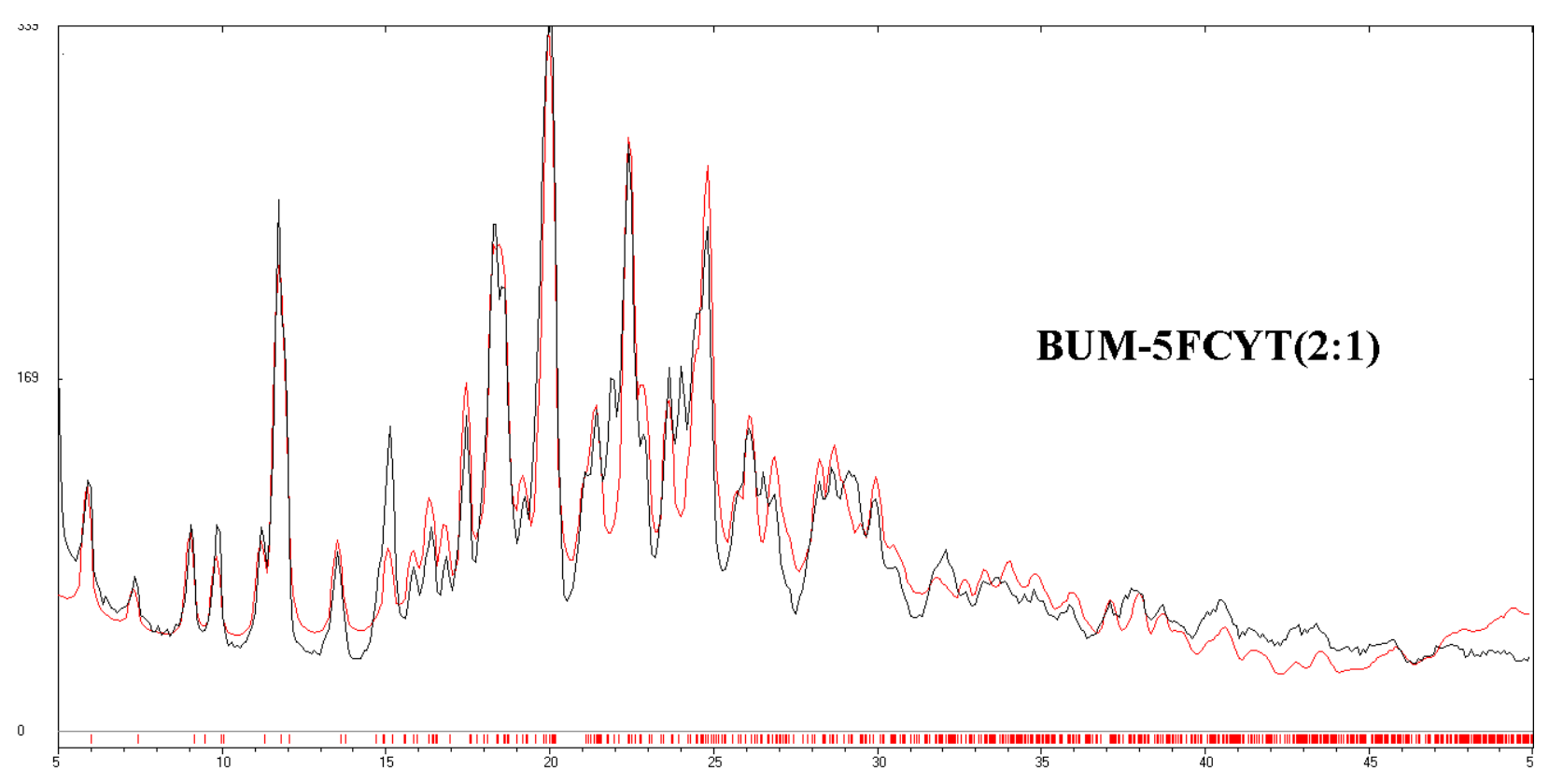

Figure S13: Overlay of BUM-5FCYT (2:1) cocrystal salt of powder pattern with calculated line pattern of the crystal structure. 


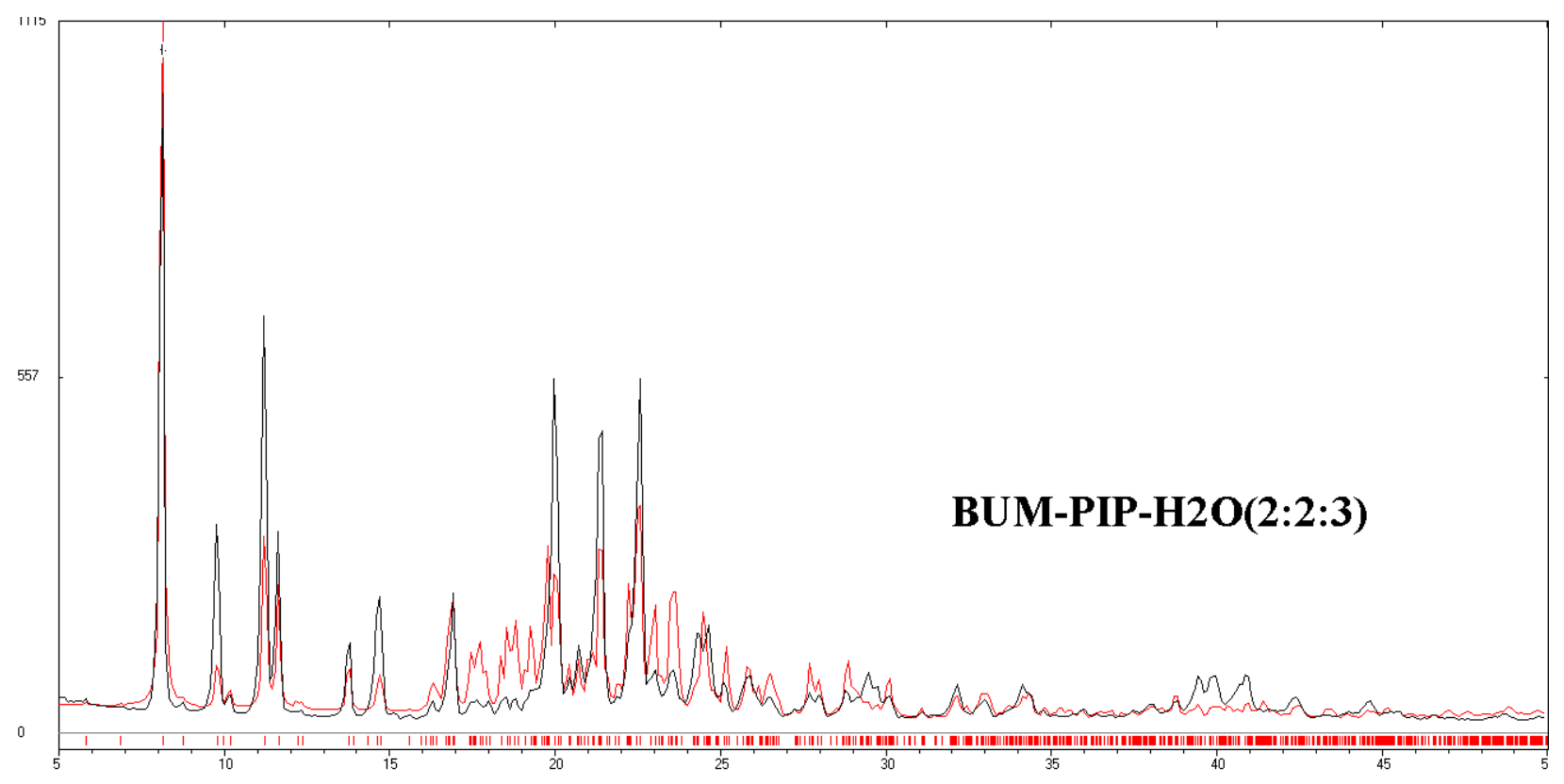

Figure S14: Overlay of BUM-PIP- $\mathrm{H}_{2} \mathrm{O}(2: 2: 3)$ salt-hydrate of powder pattern with calculated line pattern of the crystal structure.

\section{Section S3: FT-IR spectra of BUM cocrystal/salts and salt-cocrystals}

Novel BUM cocrystals and salts crystalline phases were characterized by FT-IR spectroscopy. The carboxylic acid, sulfonamide and lactams, amides functional groups $(\mathrm{C}=\mathrm{O} / \mathrm{OH} / \mathrm{NH})$ exhibit different stretching frequency.

Table S2: Selected functional group stretching frequency in FT-IR spectra of BUM cocrystalsalts.

\begin{tabular}{|c|c|c|c|}
\hline & $\begin{array}{c}\mathrm{C}=\mathrm{O} \\
(\text { carboxylic } \\
\text { acid) }(\mathrm{cm}-1)\end{array}$ & $\begin{array}{c}\text { Acid/Hydroxyl-OH/Amide } \\
\mathrm{NH}\left(\mathrm{cm}^{-1}\right)\end{array}$ & $\begin{array}{c}\mathrm{NH} \mathrm{in} \mathrm{SO}_{2} \mathrm{NH}_{2} \\
\left(\mathrm{~cm}^{-1}\right)\end{array}$ \\
\hline BUM & 1695 & 3401 & 3292 \\
\hline BUM-VLM (1:1) & 1687 & 3359 & 3194 \\
\hline BUM-CPR (1:1) & 1689 & 3377 & 3210 \\
\hline BUM-NMeCPR (2:1) & 1688 & 3375 & 3311 \\
\hline BUM-UREA (1:1) & 1672 & 3365 & 3179 \\
\hline
\end{tabular}




\begin{tabular}{|c|c|c|c|}
\hline $\begin{array}{c}\text { BUM } \\
- \text { BUM-5FCYTH } \\
(1: 1: 1)\end{array}$ & 1692 & 3384 & 3204 \\
\hline $\begin{array}{c}\text { BUM-4AP }(1: 1) \\
\begin{array}{c}\text { BUM-PIP- }{ }_{2} \mathrm{O} \\
(2: 2: 3)\end{array}\end{array}$ & 1665 & 3337 & 3187 \\
\hline VLM & 1632 & 3375 & 3293 \\
\hline CPR & 1636 & 3273 & -- \\
\hline NMeCPR & 1627 & 3429 & -- \\
\hline UREA & 1683 & --- & -- \\
\hline 5 FCYT & 1685 & 3442,3346 & -- \\
\hline 4 AP & -- & 3372 & -- \\
\hline PIP & -- & 3436 & -- \\
\hline
\end{tabular}

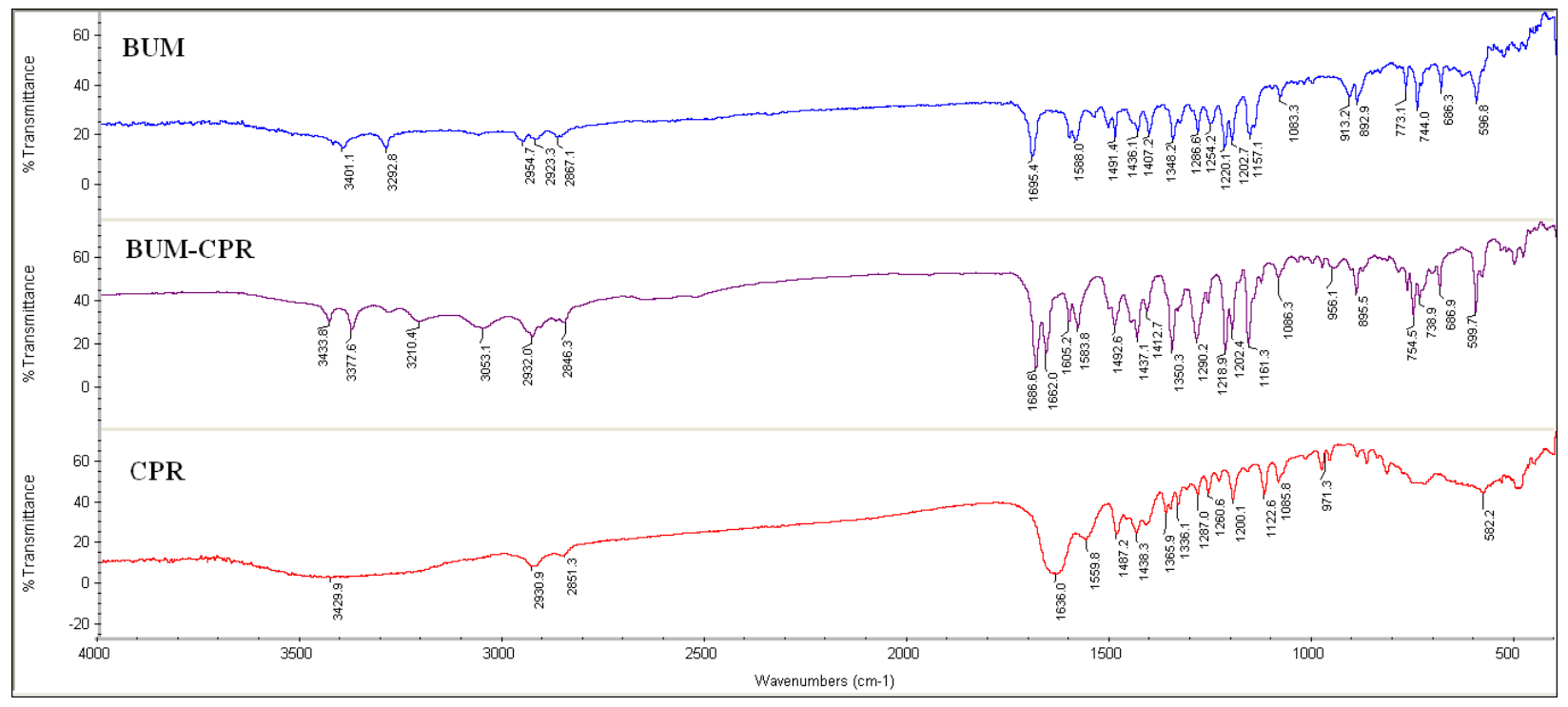

Figure S15: IR comparison of BUM-CPR (1:1) cocrystal. 


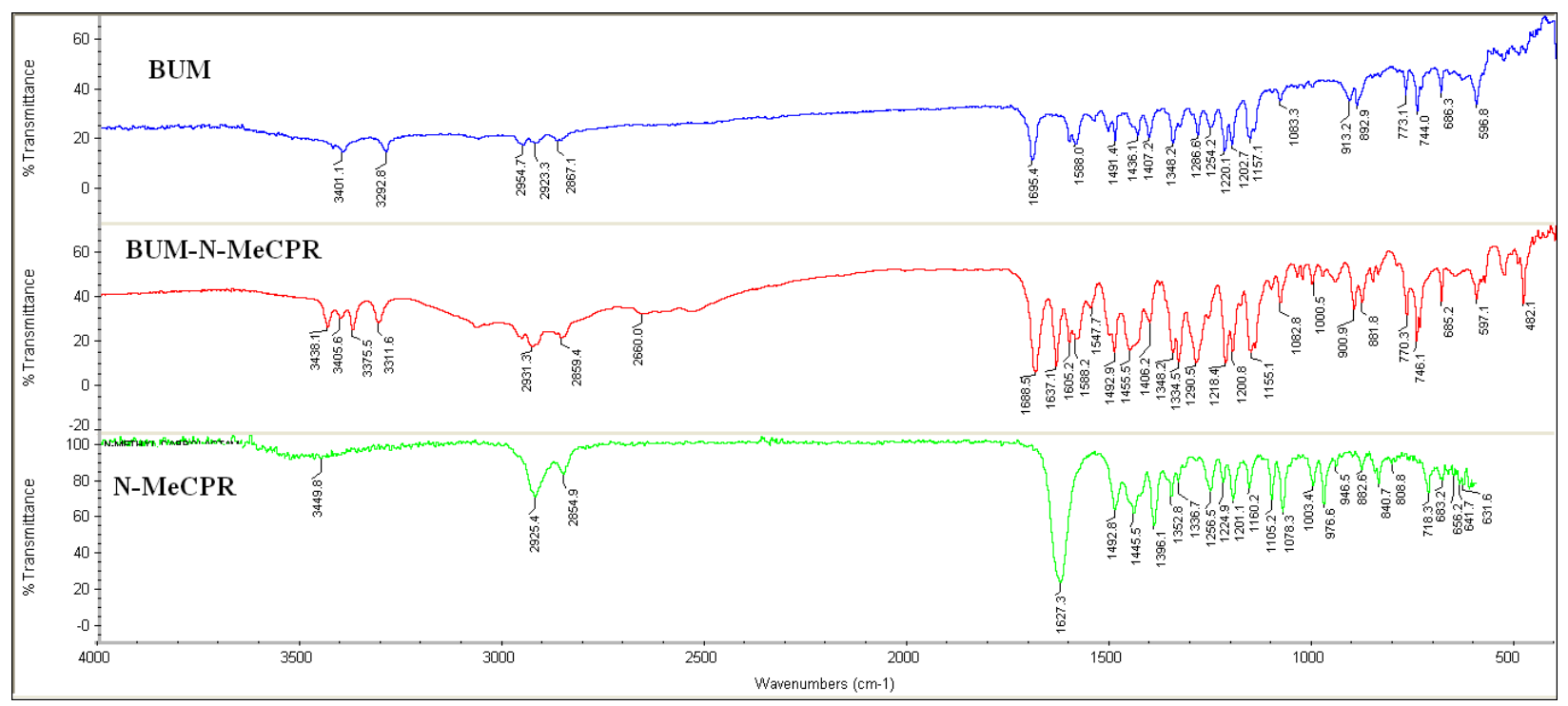

Figure S16: IR comparison of BUM-N-MeCPR (2:1) cocrystal.

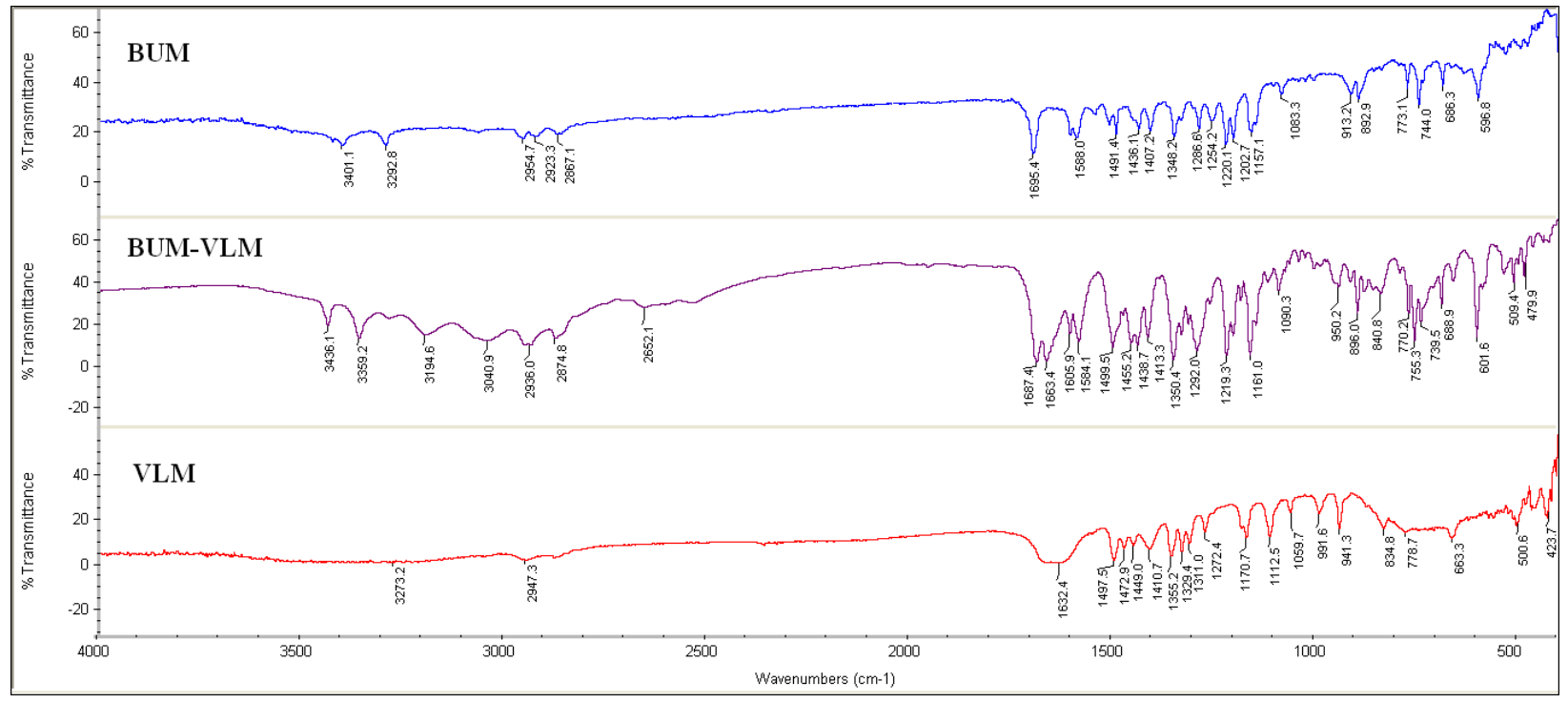

Figure S17: IR comparison of BUM-VLM (1:1) cocrystal. 


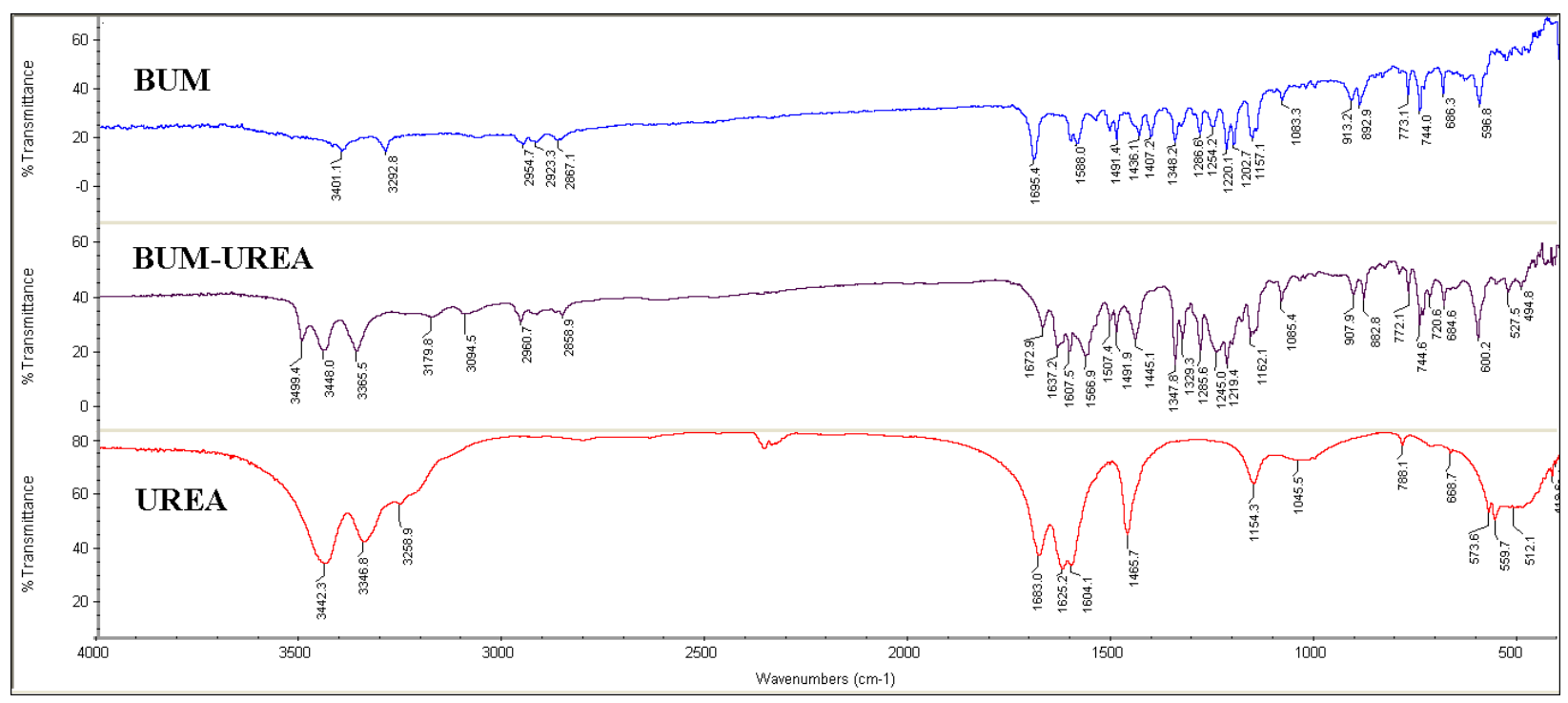

Figure S18: IR comparison of BUM-UREA (1:1) cocrystal.

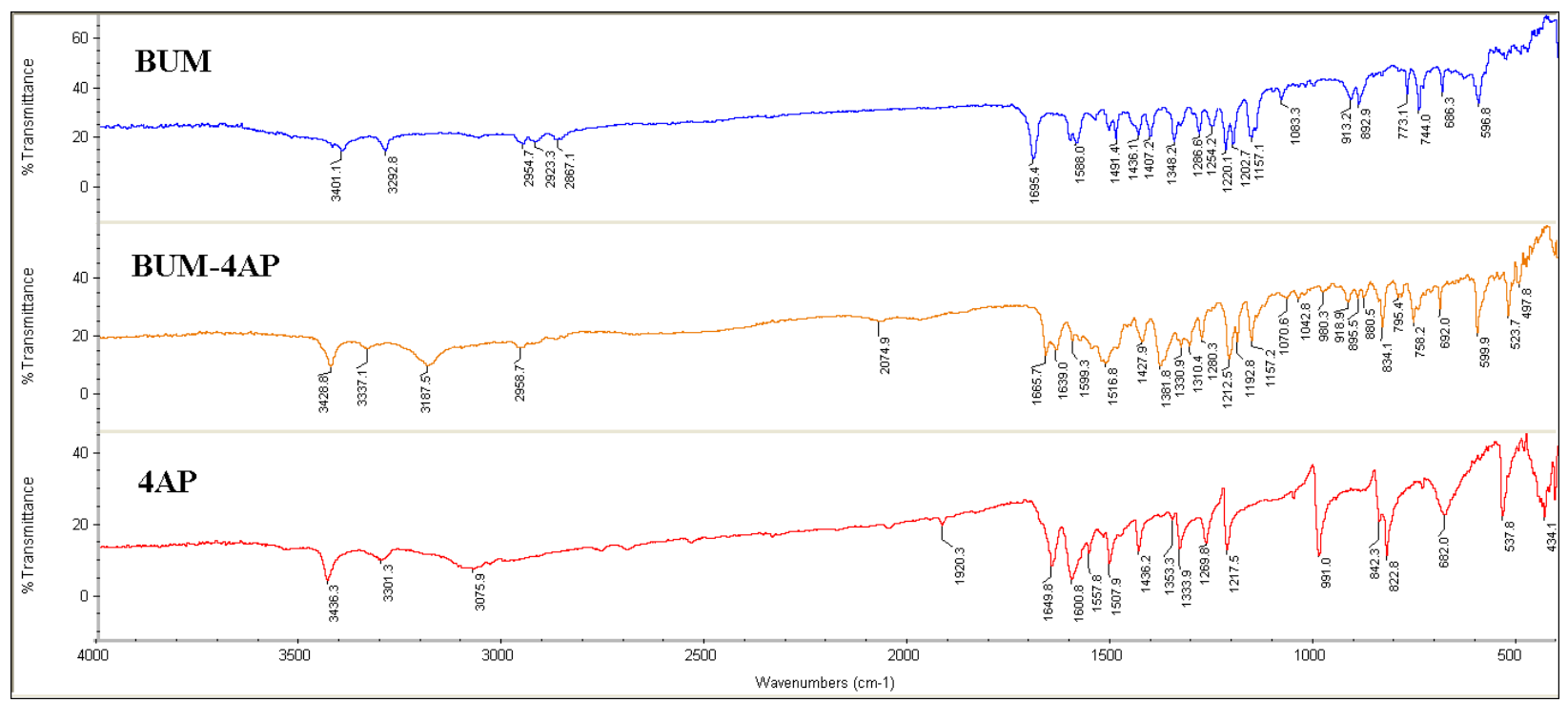

Figure S19: IR comparison of BUM-4AP (1:1) salt. 


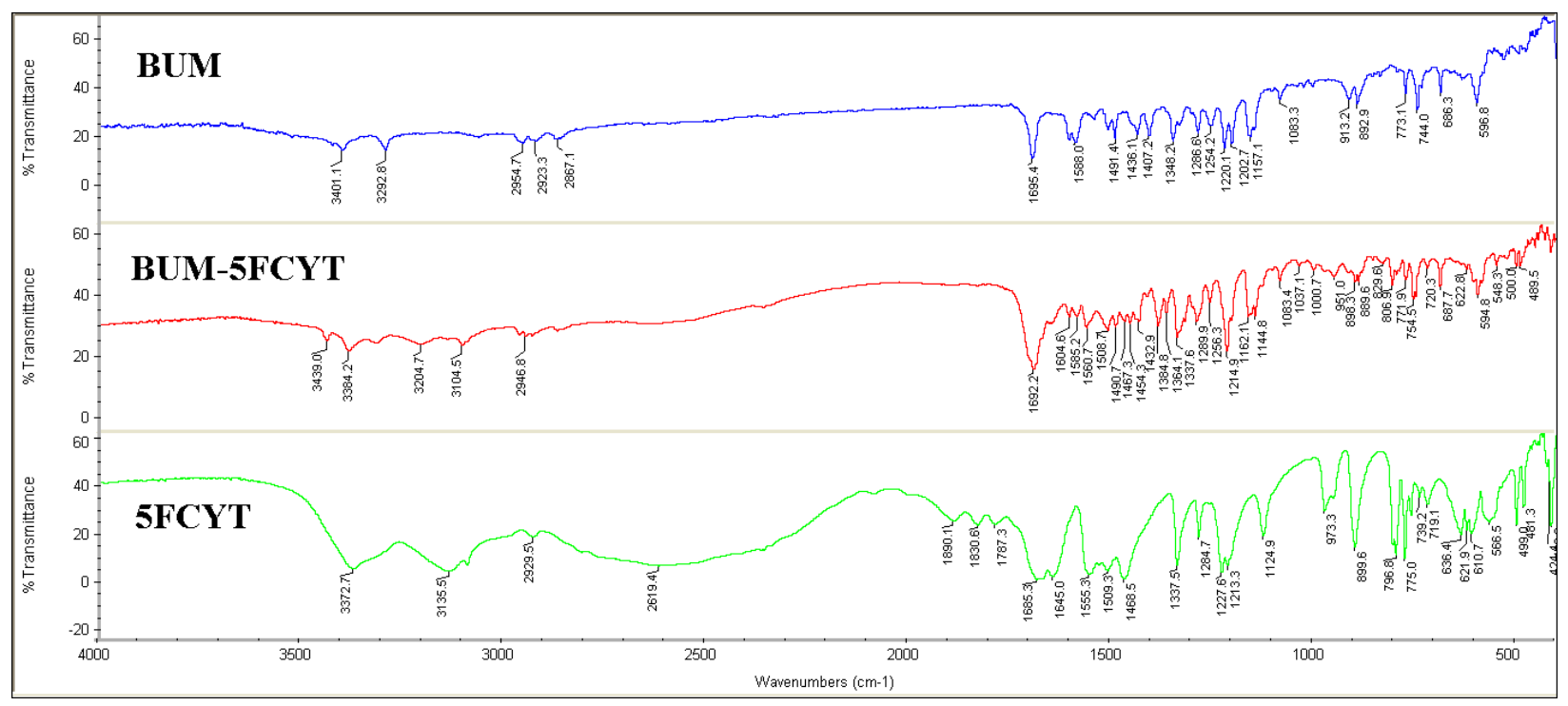

Figure S20: IR comparison of BUM-5FCYT (2:1) cocrystal salt.

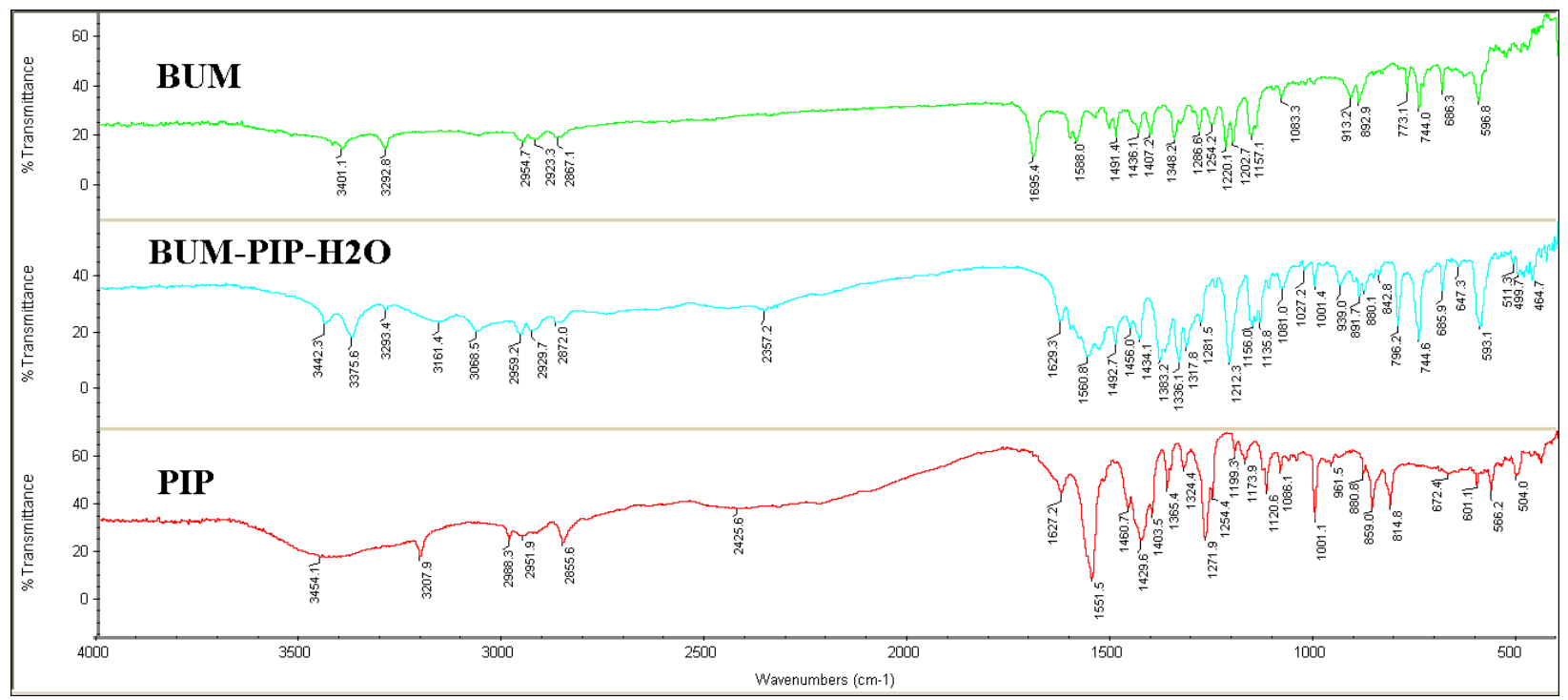

Figure S21: IR comparison of BUM-PIP- $\mathrm{H}_{2} \mathrm{O}(2: 2: 3)$ cocrystal salt. 
Section S4: DSC of BUM cocrystal/salts and salt-cocrystals.

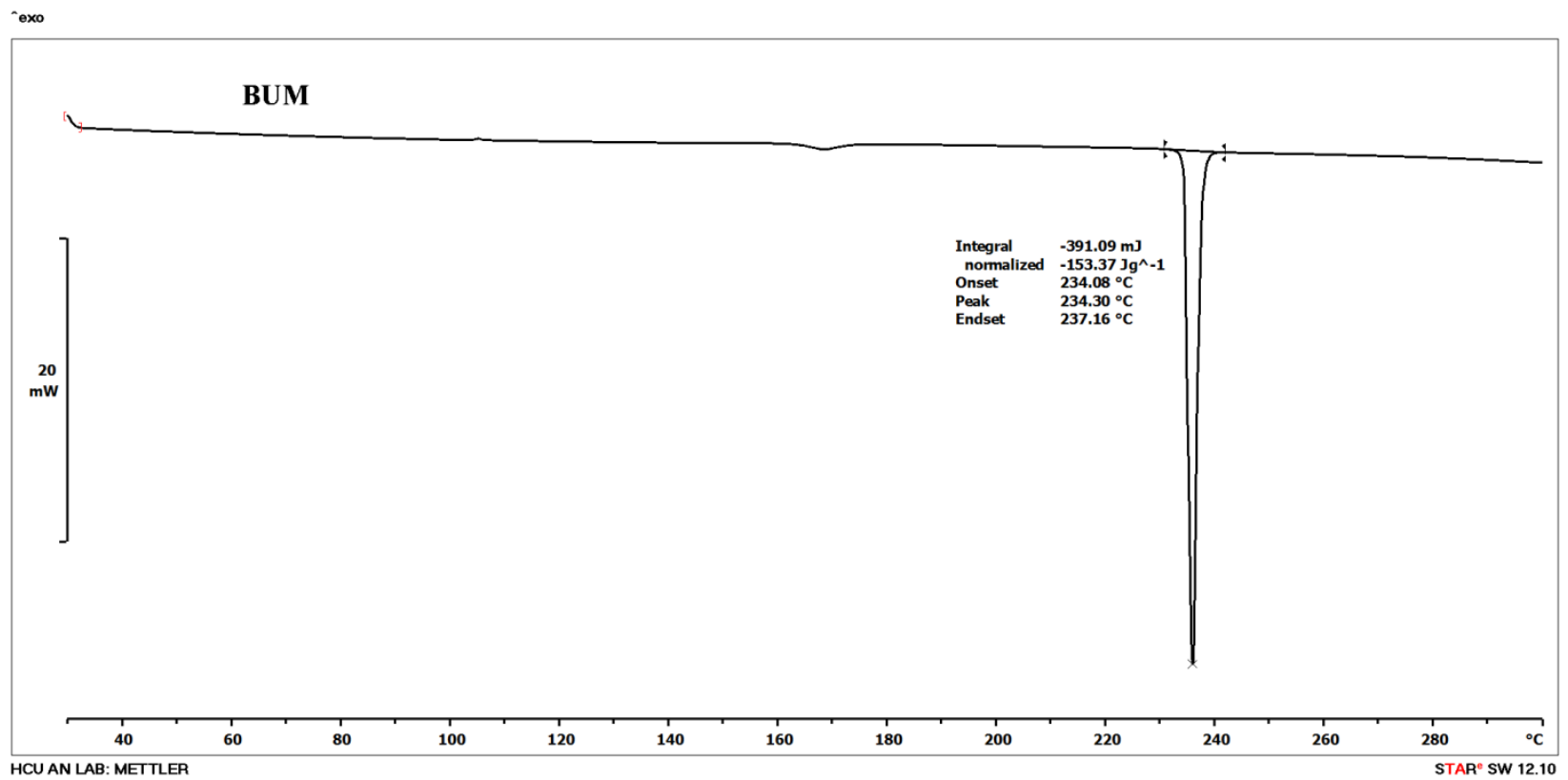

Figure S22: BUM.

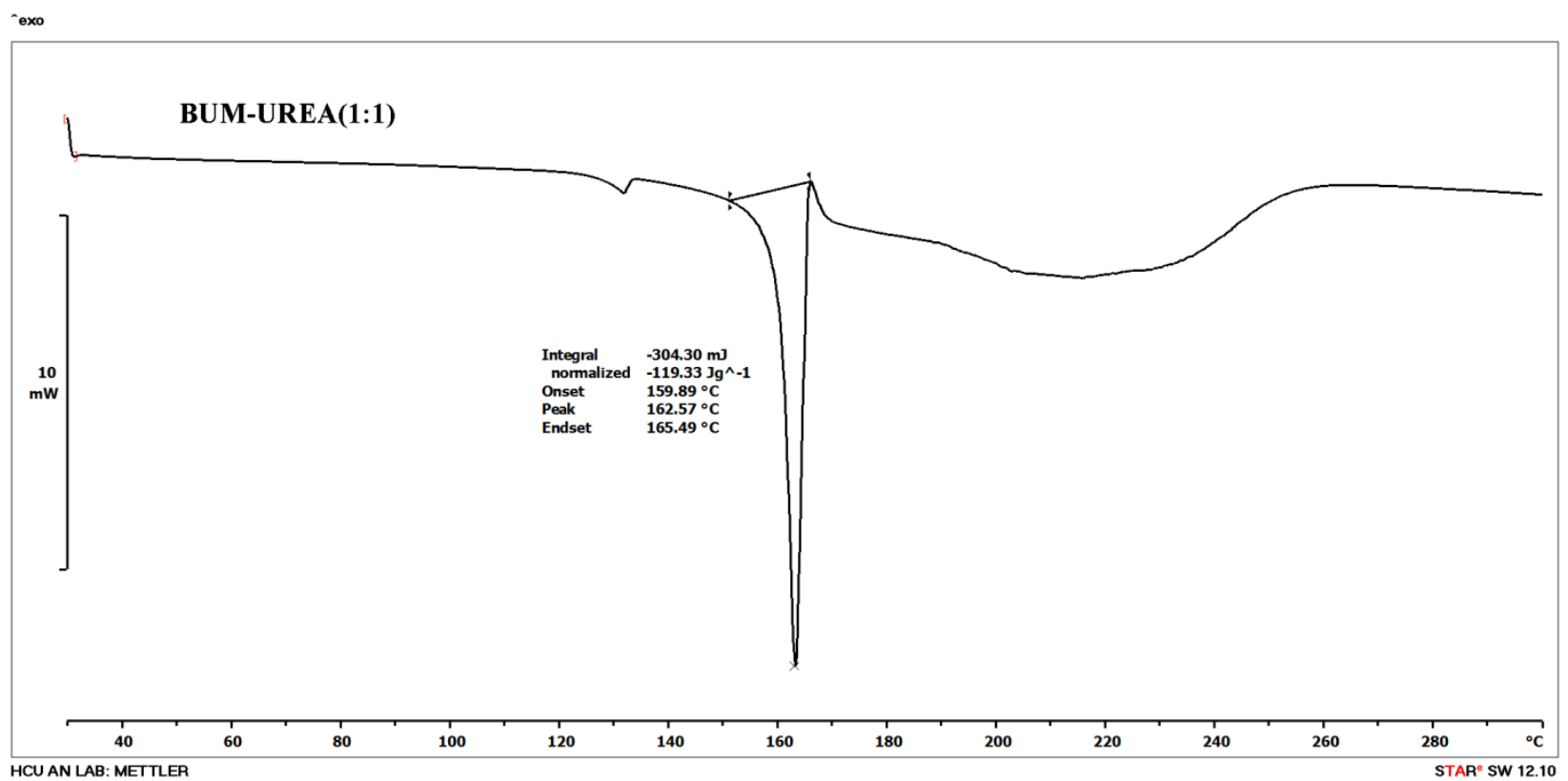

Figure S23: BUM-UREA (1:1). 


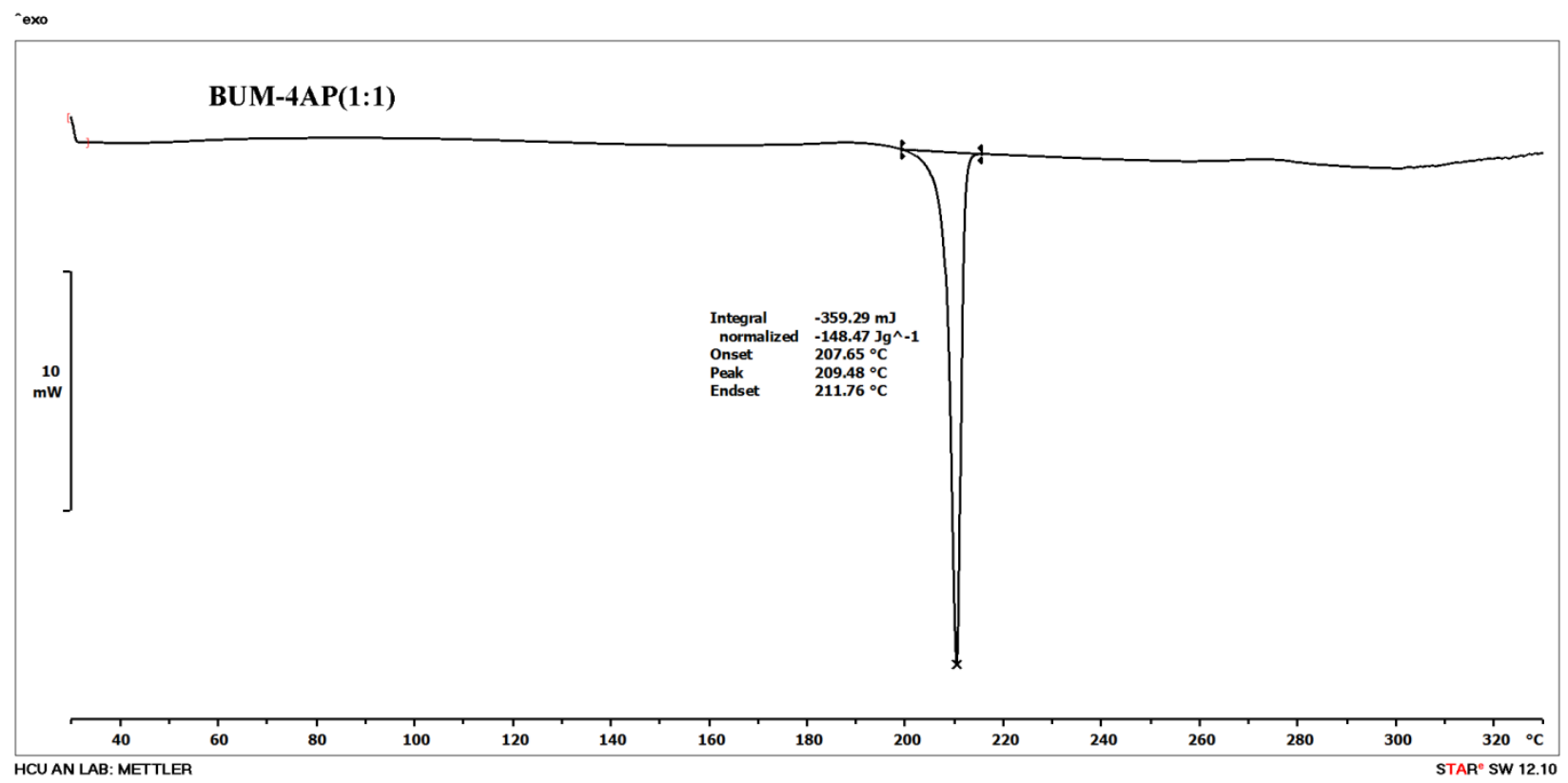

Figure S24: BUM-4AP (1:1).

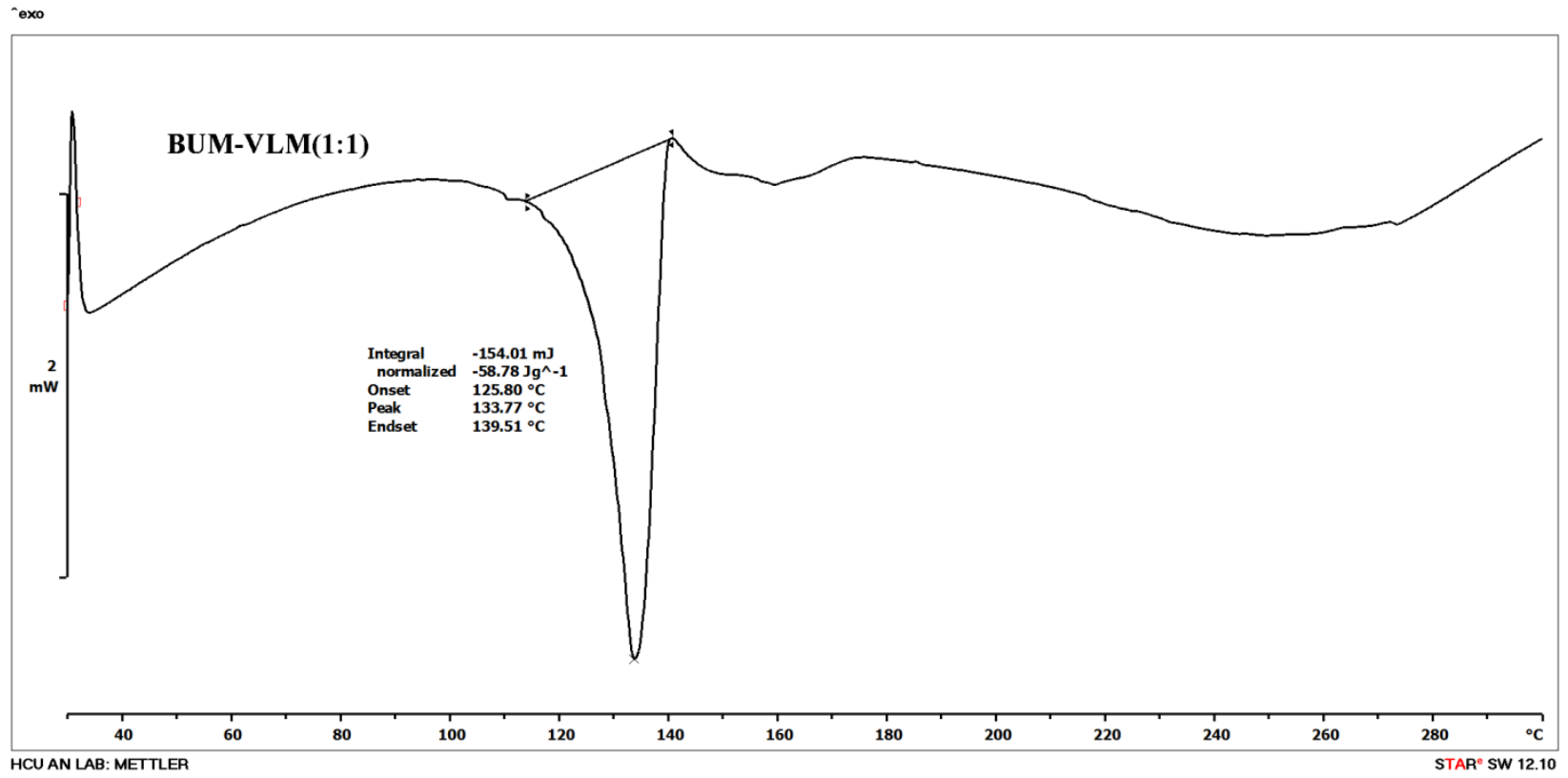

Figure S25: BUM-VLM (1:1). 


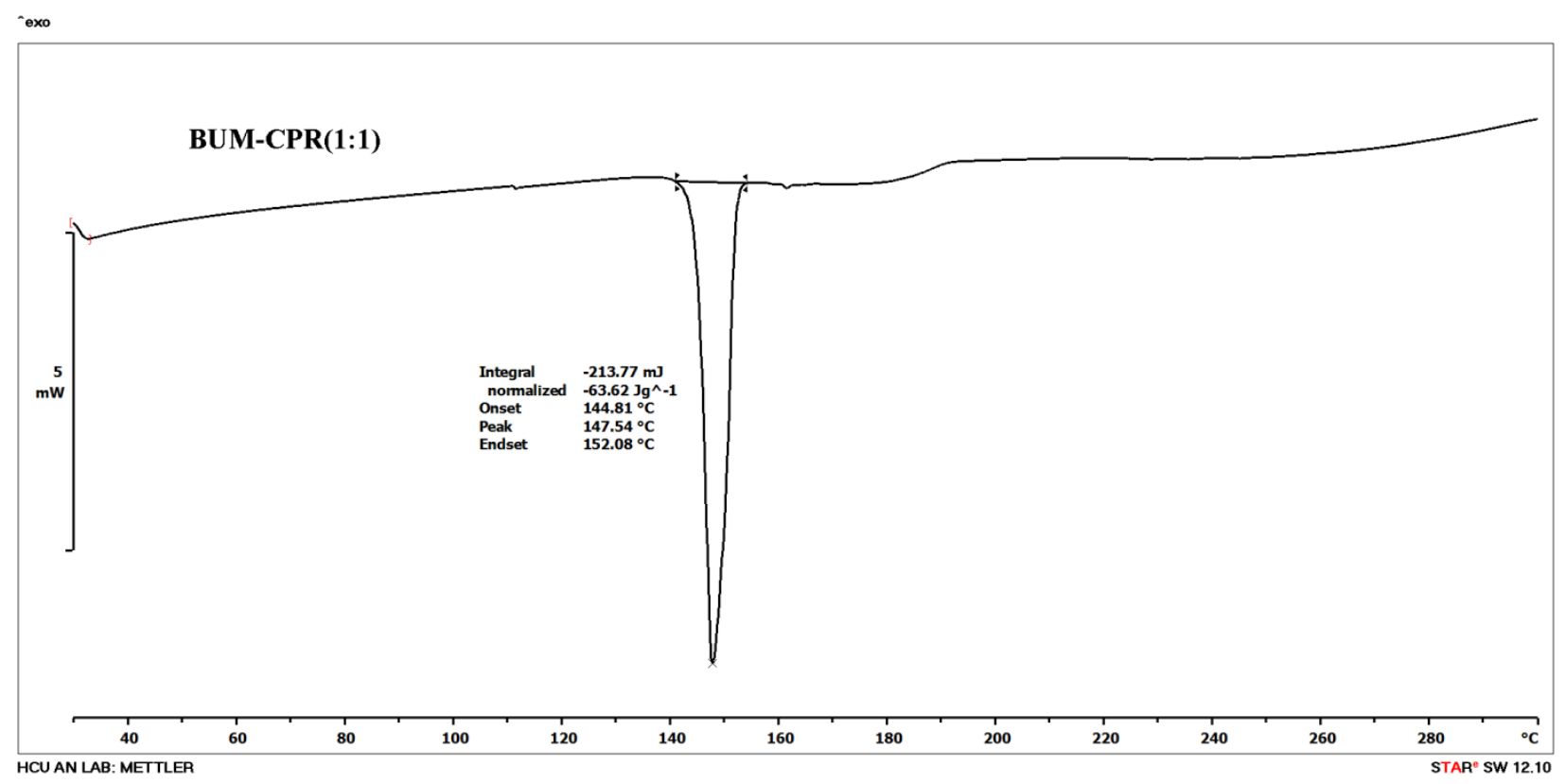

Figure S26: BUM-CPR (1:1).

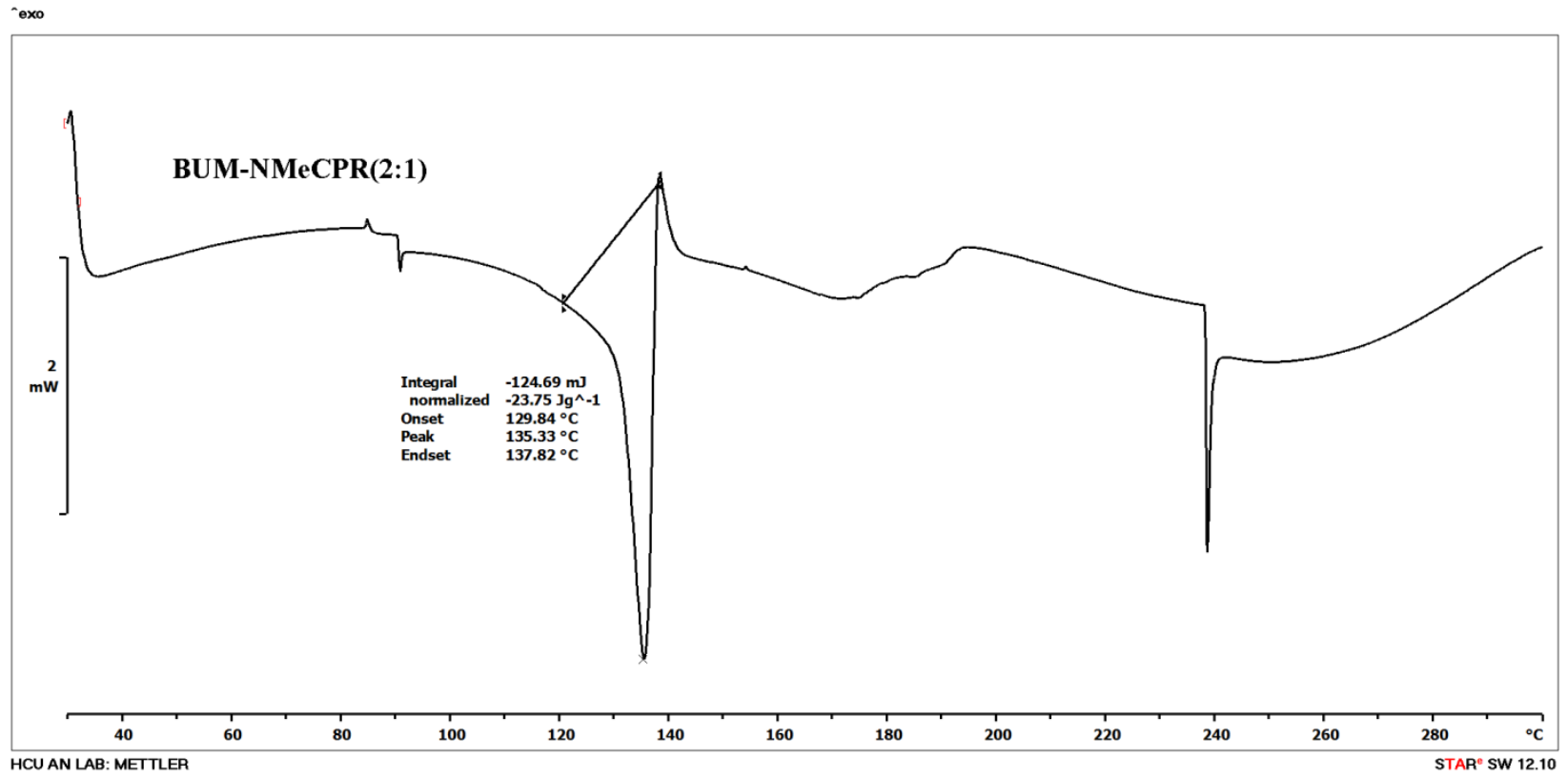

Figure S27: BUM-NMeCPR (2:1). 


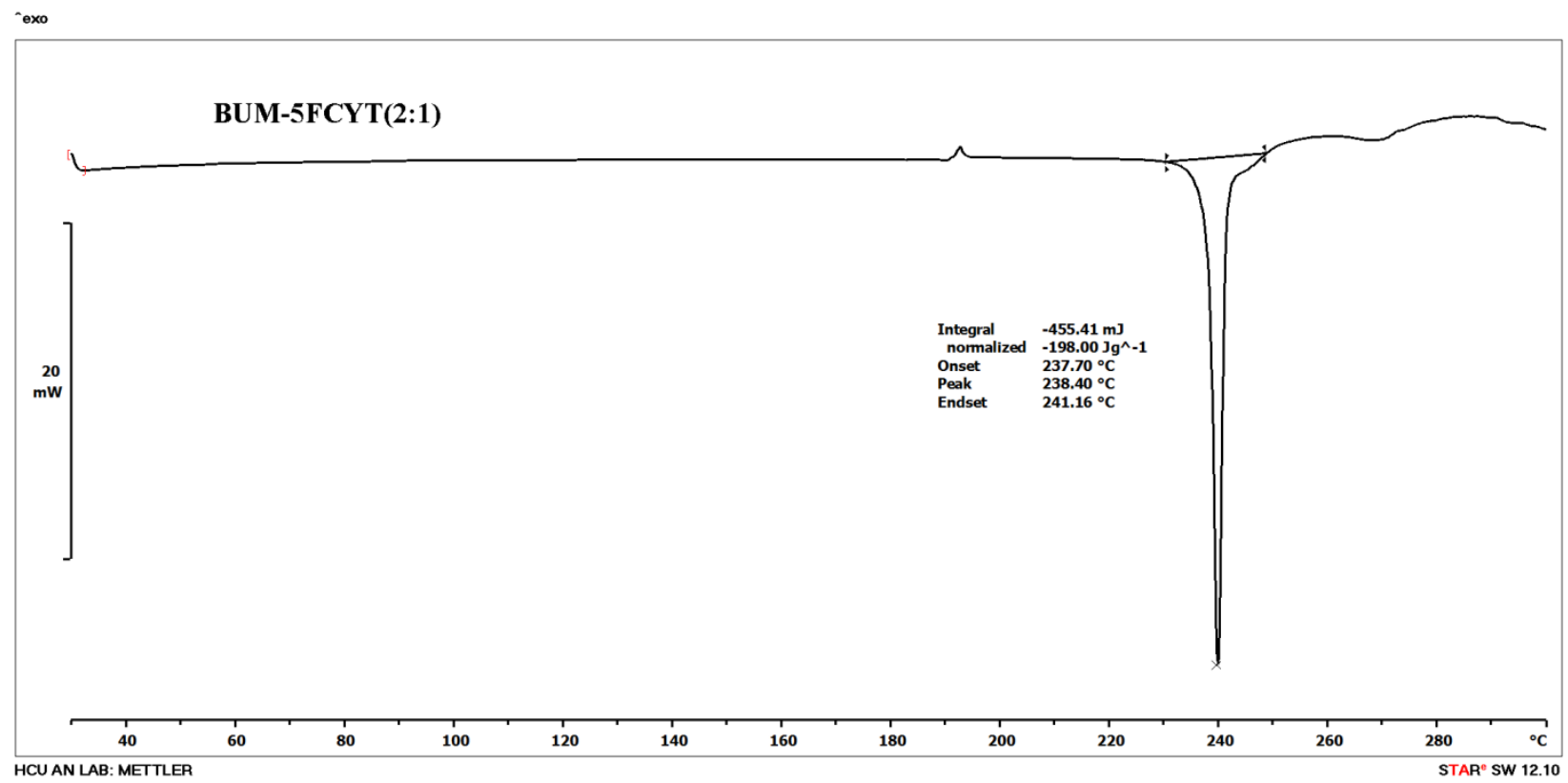

Figure S28: BUM-5FCYT (2:1),

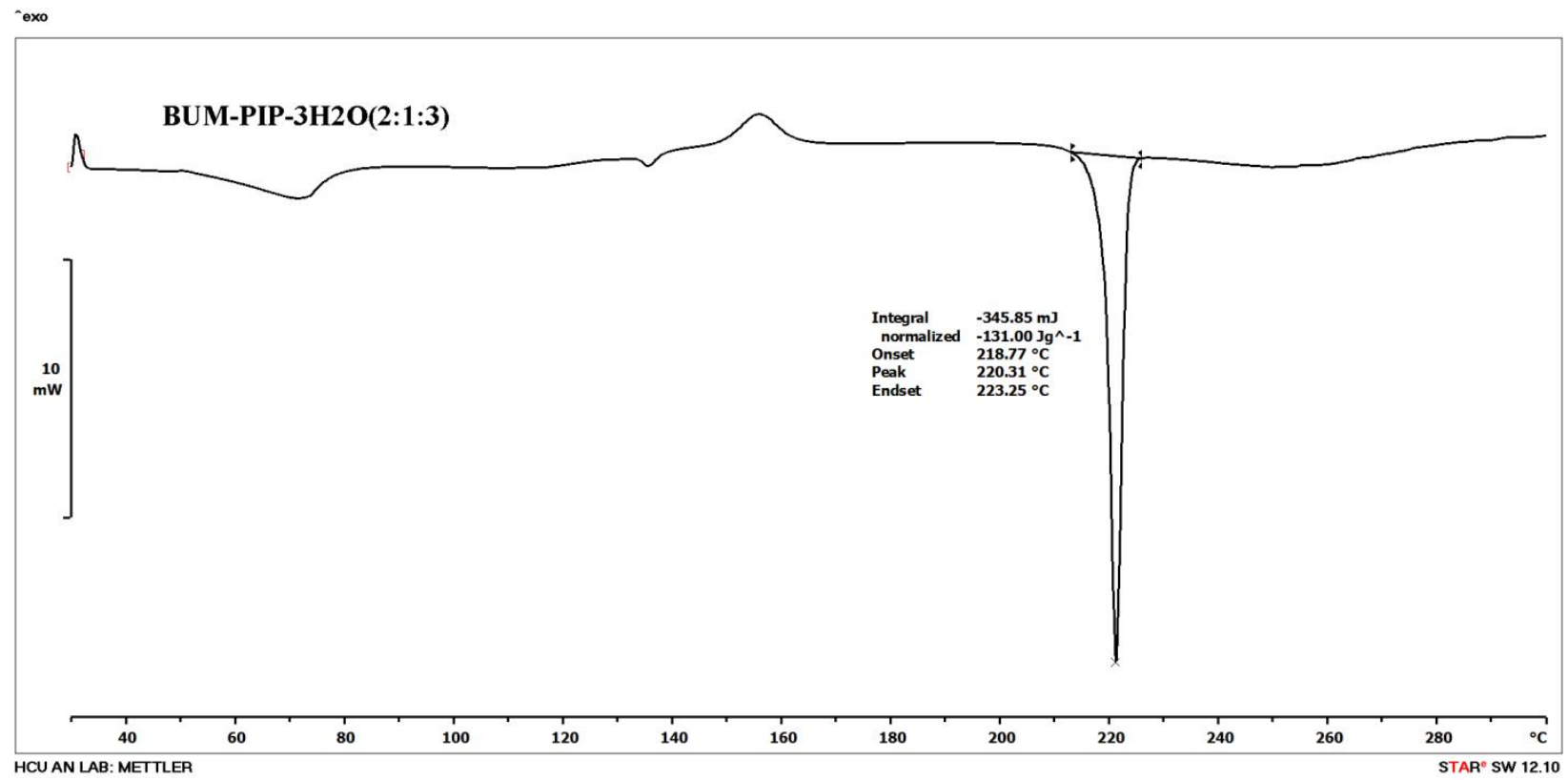

Figure S29: $\mathrm{BUM}-\mathrm{PIP}-\mathrm{H}_{2} \mathrm{O}(2: 2: 3)$. 


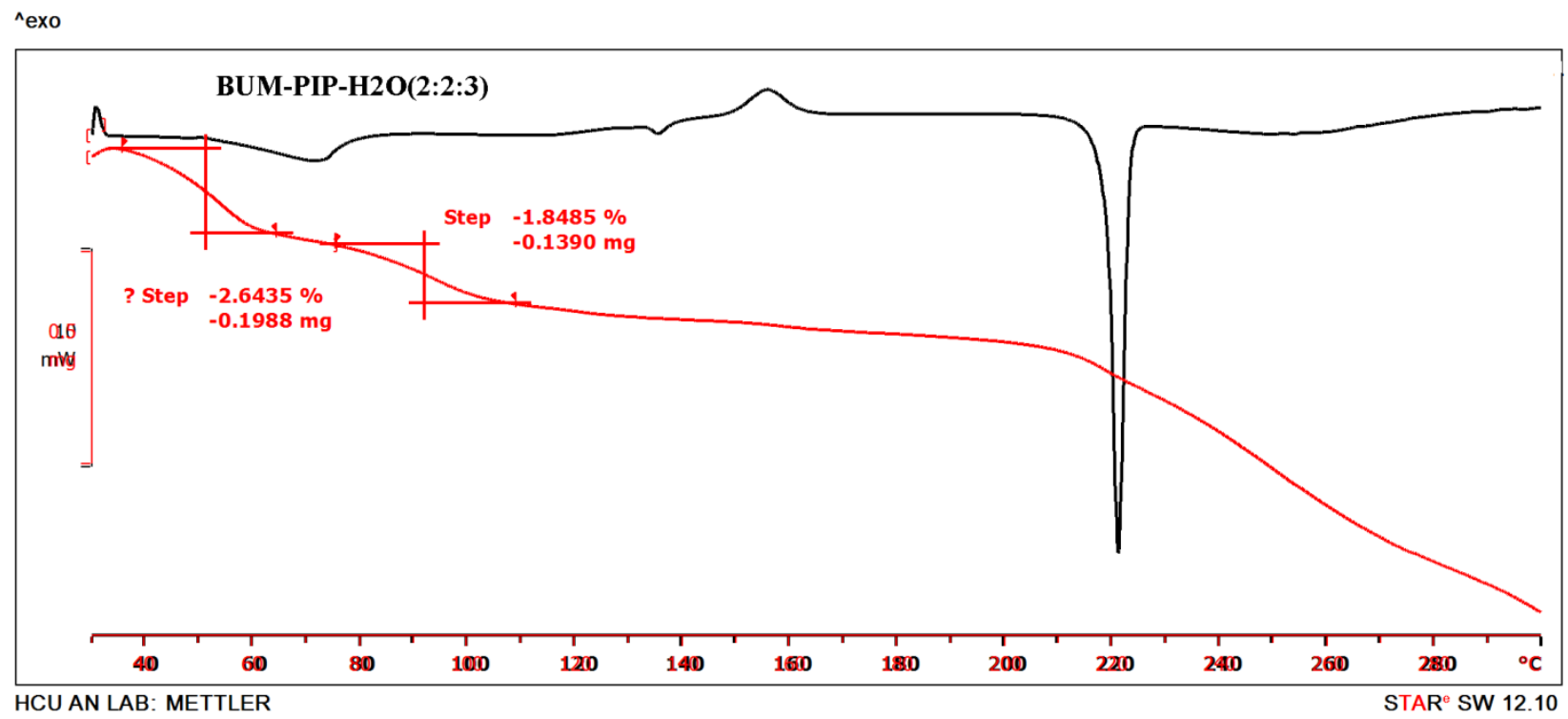

Figure S30: BUM-PIP- $\mathrm{H}_{2} \mathrm{O}(2: 2: 3)$ DSC and TGA.

Section S5: PXRD analysis to determine crystal form phase stability at 24 h (equilibrium solubility) and $8 \mathrm{~h}$ (dissolution) in pH 7 buffer media.

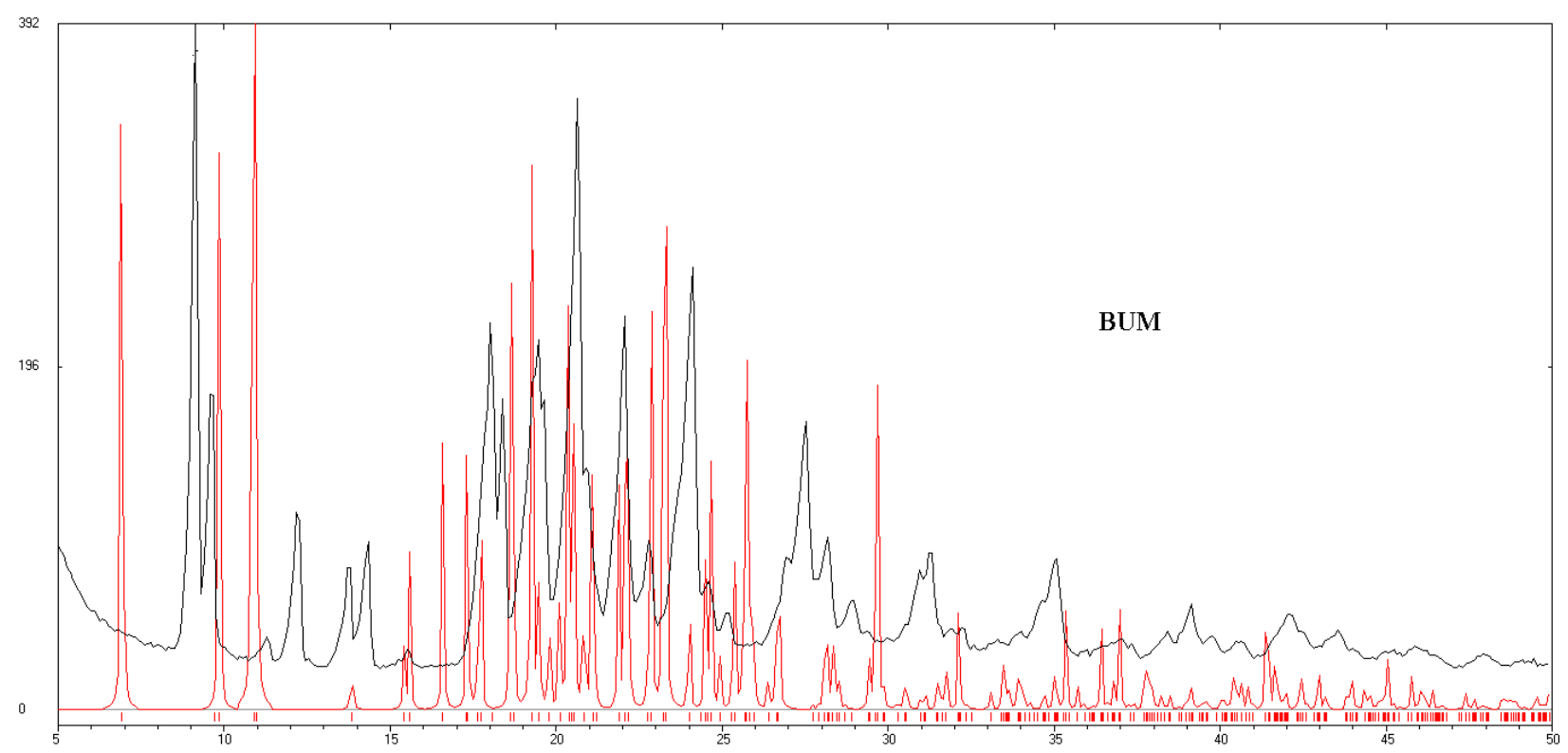

Figure S31: Overlay of calculated PXRD of BUM and experimental PXRD of commercially available BUM used in this study. They are different polymorphs clearly. 


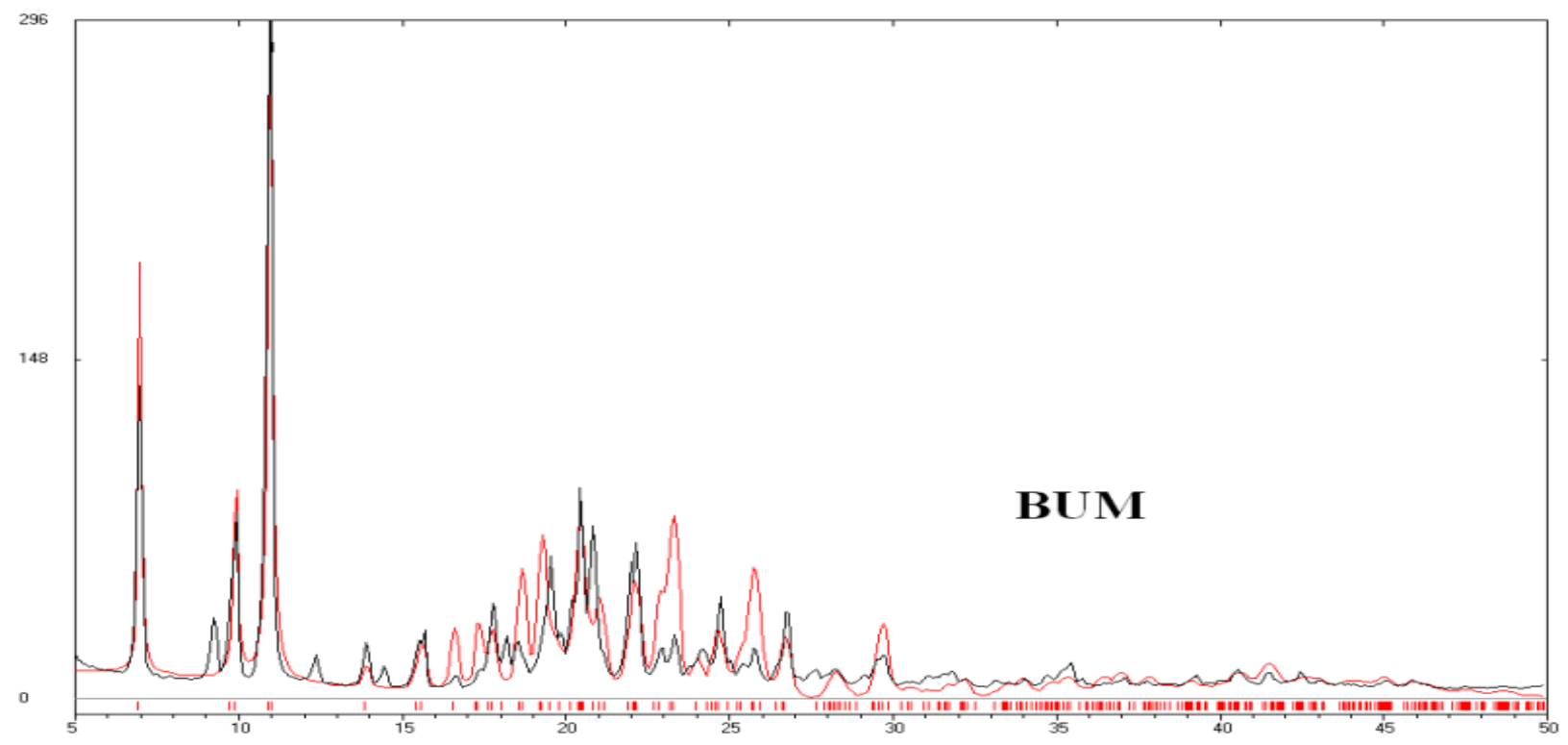

Figure S32: Overlay of calculated PXRD of BUM and experimental PXRD after 24 hours slurry experiment. There are small new peaks at 9.2 and $12.5^{\circ} 2 \theta$, the major peaks are matching. Hence the commercially available BUM form does not completely convert to the stable BUM form after 24 hours slurry crystallization in ethyl acetate (EtOAc) solvent, then the experiment was continued until 72 h (see Figure S33).

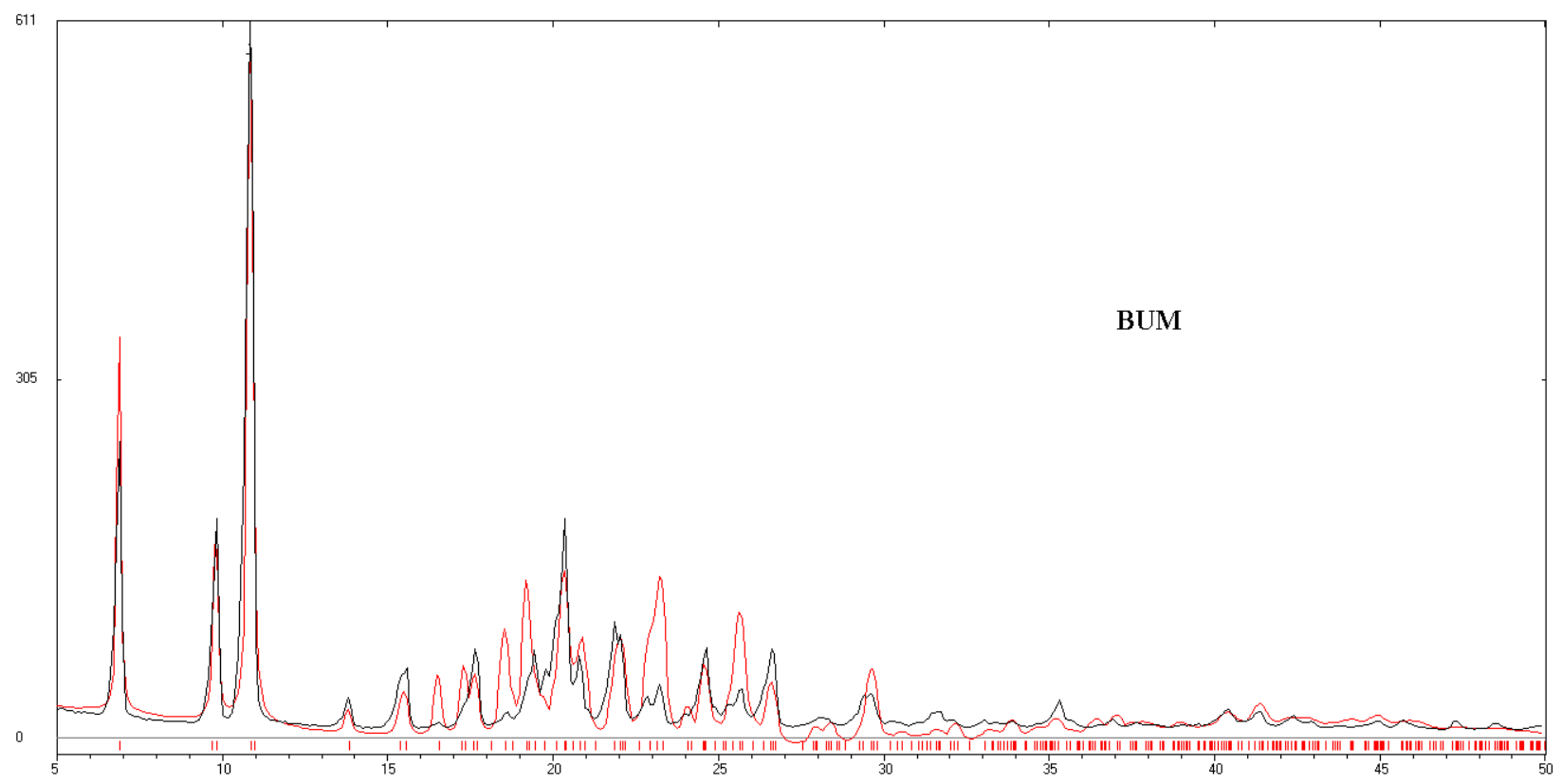

Figure S33: Overlay of calculated PXRD of BUM and experimental PXRD after 72 hours slurry experiment. Hence the commercially available BUM form converts to the stable BUM form after 72 hours slurry crystallization experiment in ethyl acetate (EtOAc) solvent. 


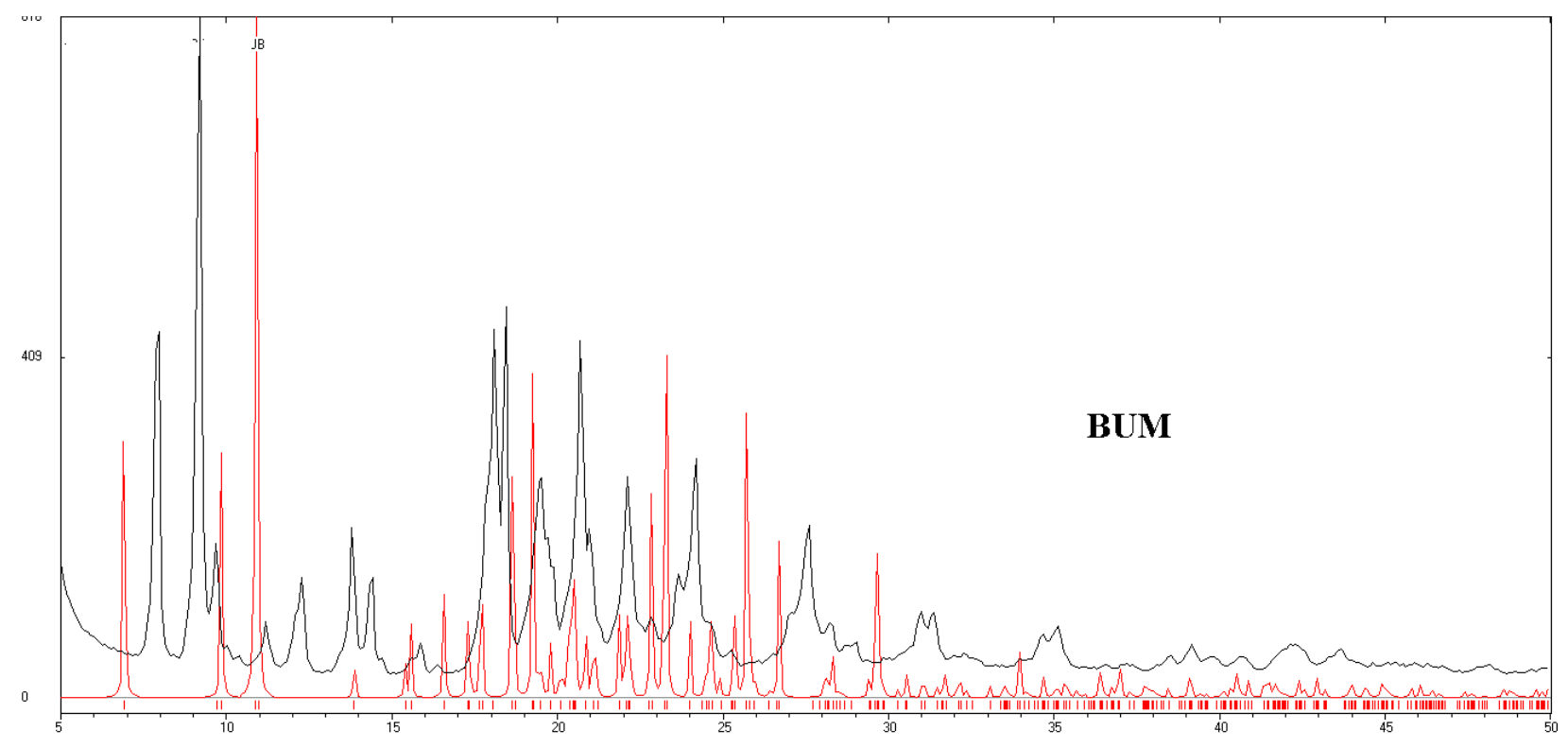

Figure S34: PXRD of BUM at the end of equilibrium solubility/ phase stability experiment (24 h black) in pH 7.0 buffer medium does not matches with the calculated XRD pattern of BUM (red) of starting material indicating new phase of BUM. Hence the commercially available BUM form converts to the stable BUM phase.

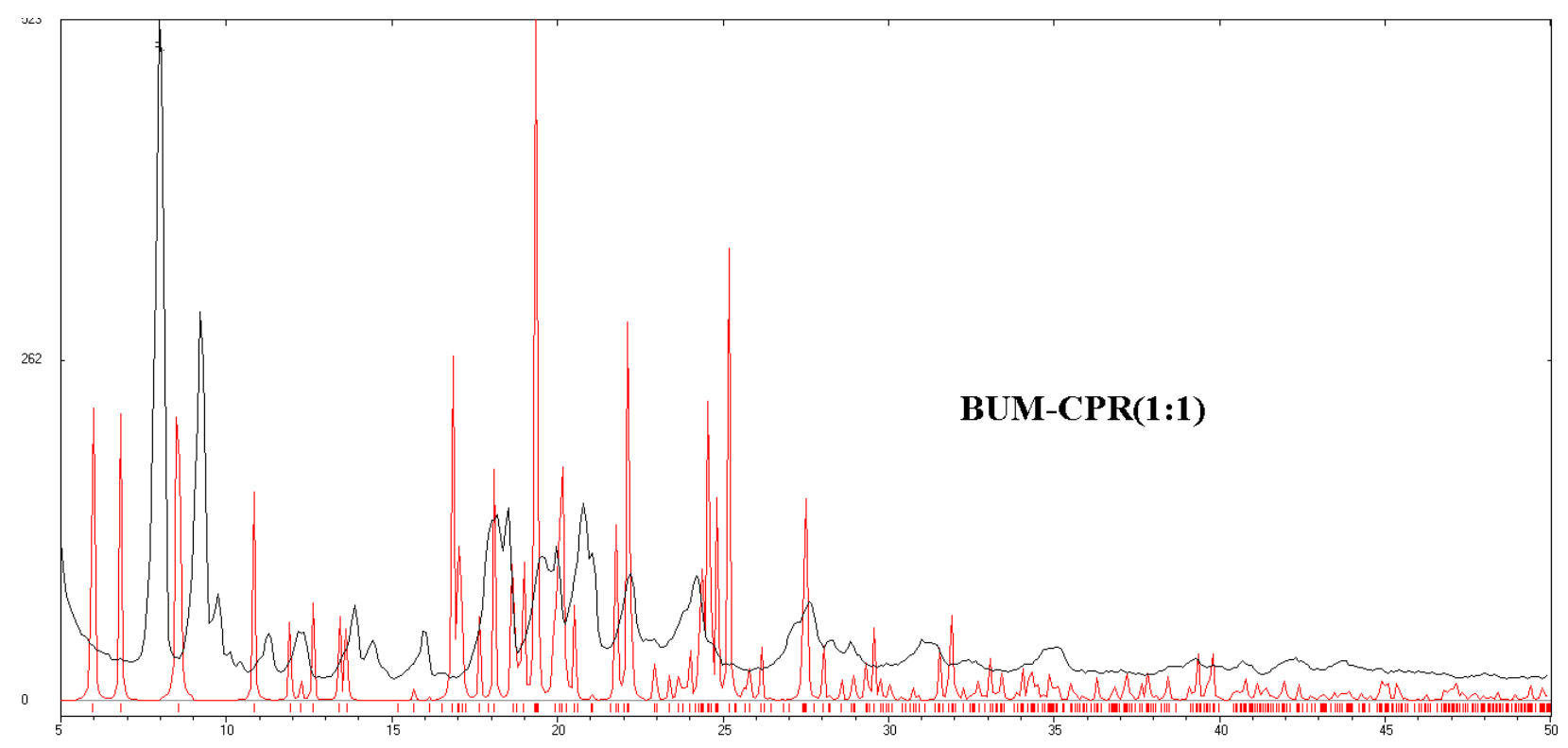

Figure S35 PXRD of BUM-CPR(1:1) at the end of equilibrium solubility/ phase stability experiment ( $24 \mathrm{~h}$ black) in $\mathrm{pH} 7.0$ buffer medium does not matches with the calculated XRD pattern of BUM-CPR(1:1) (red) of starting material indicating new phase or BUM adduct of buffer. 


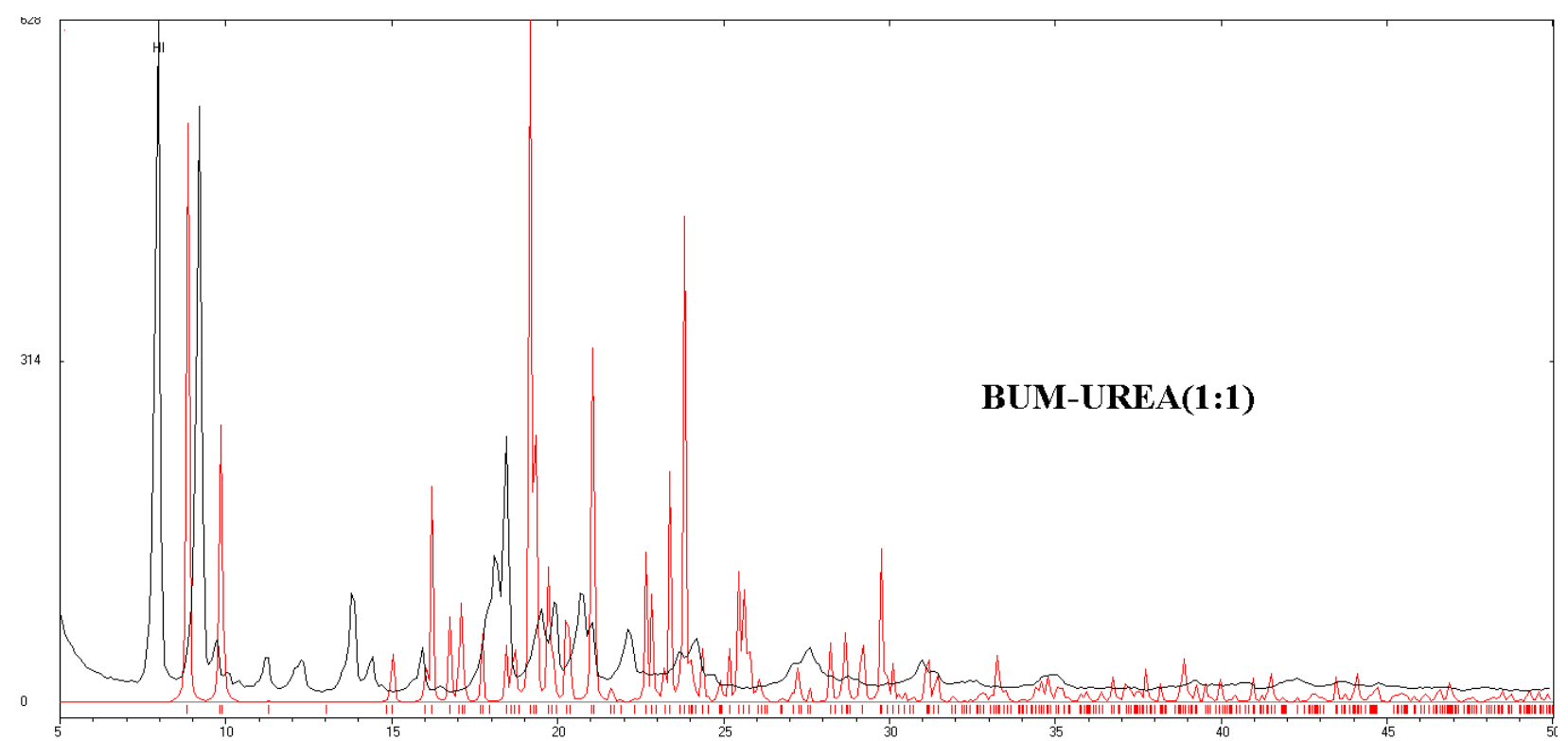

Figure S36 PXRD of BUM-UREA(1:1) at the end of equilibrium solubility/ phase stability experiment ( $24 \mathrm{~h}$ black) in $\mathrm{pH} 7.0$ buffer medium does not matches with the calculated XRD pattern of BUM-CPR (1:1) (red) of starting material indicating a new phase of BUM adduct with buffer.

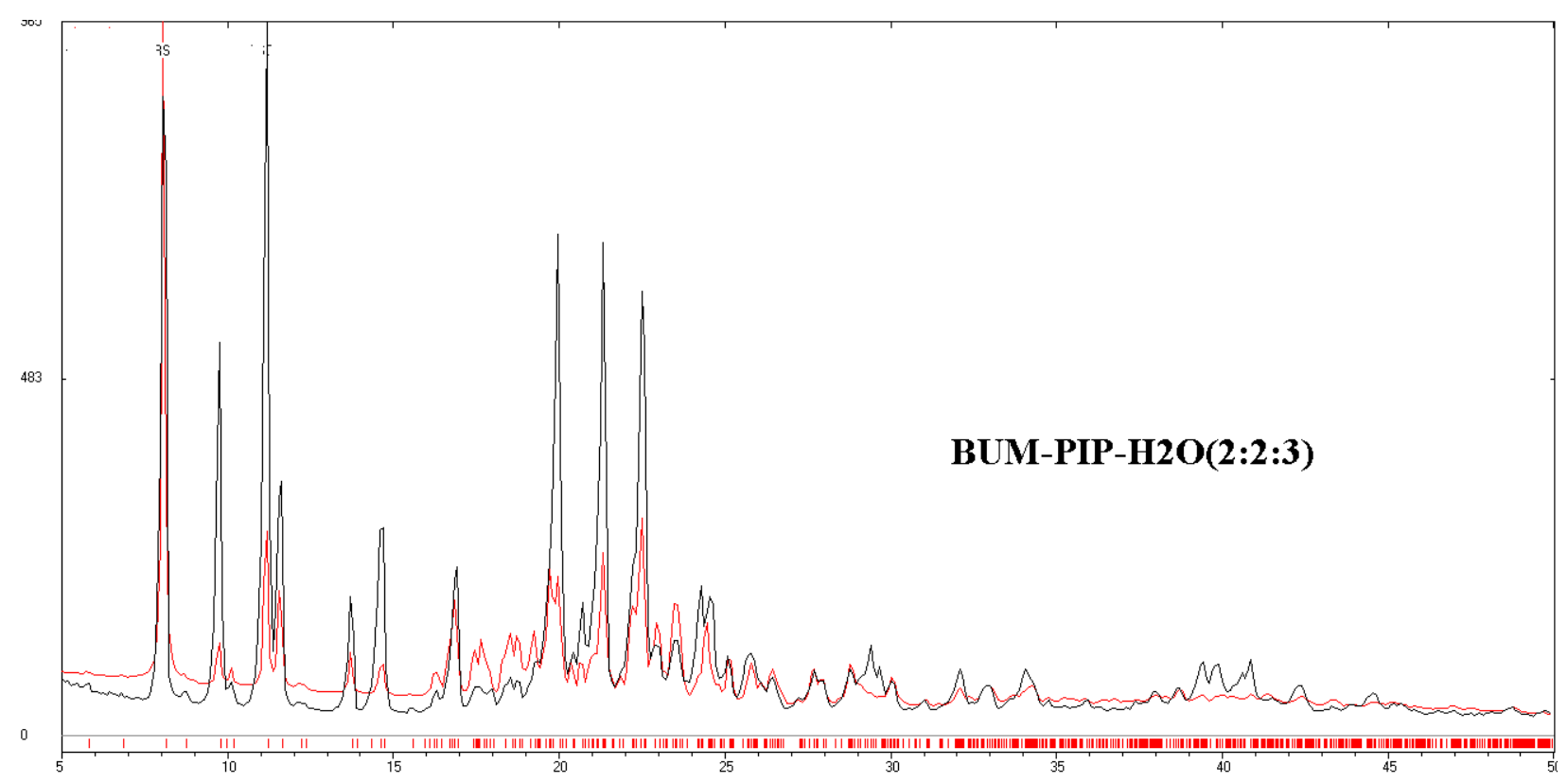

Figure S37: PXRD of BUM-PIP- $\mathrm{H}_{2} \mathrm{O}(2: 2: 3)$ at the end of equilibrium solubility/ phase stability experiment $(24 \mathrm{~h}$ black) in $\mathrm{pH} 7.0$ buffer medium matches with the calculated PXRD pattern of $\mathrm{BUM}-\mathrm{PIP}-\mathrm{H}_{2} \mathrm{O}(2: 2: 3)$ (red) of starting material indicating phase stability. 


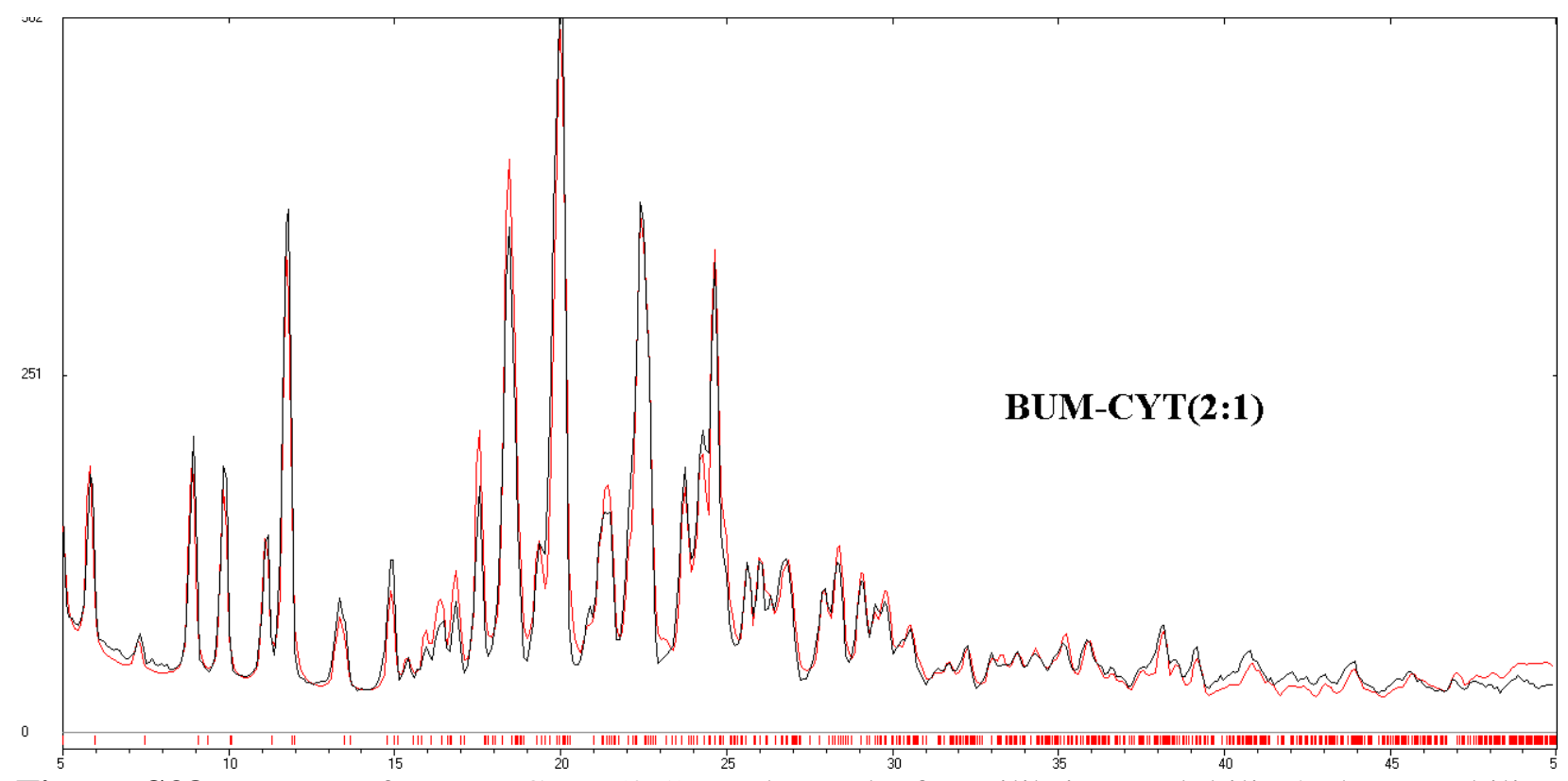

Figure S38: PXRD of BUM-CYT (2:1) at the end of equilibrium solubility/ phase stability experiment ( $24 \mathrm{~h}$ black) in $\mathrm{pH} 7.0$ buffer medium its matches with the calculated PXRD pattern of BUM-CYT (2:1) (red) of starting material indicating phase stability.

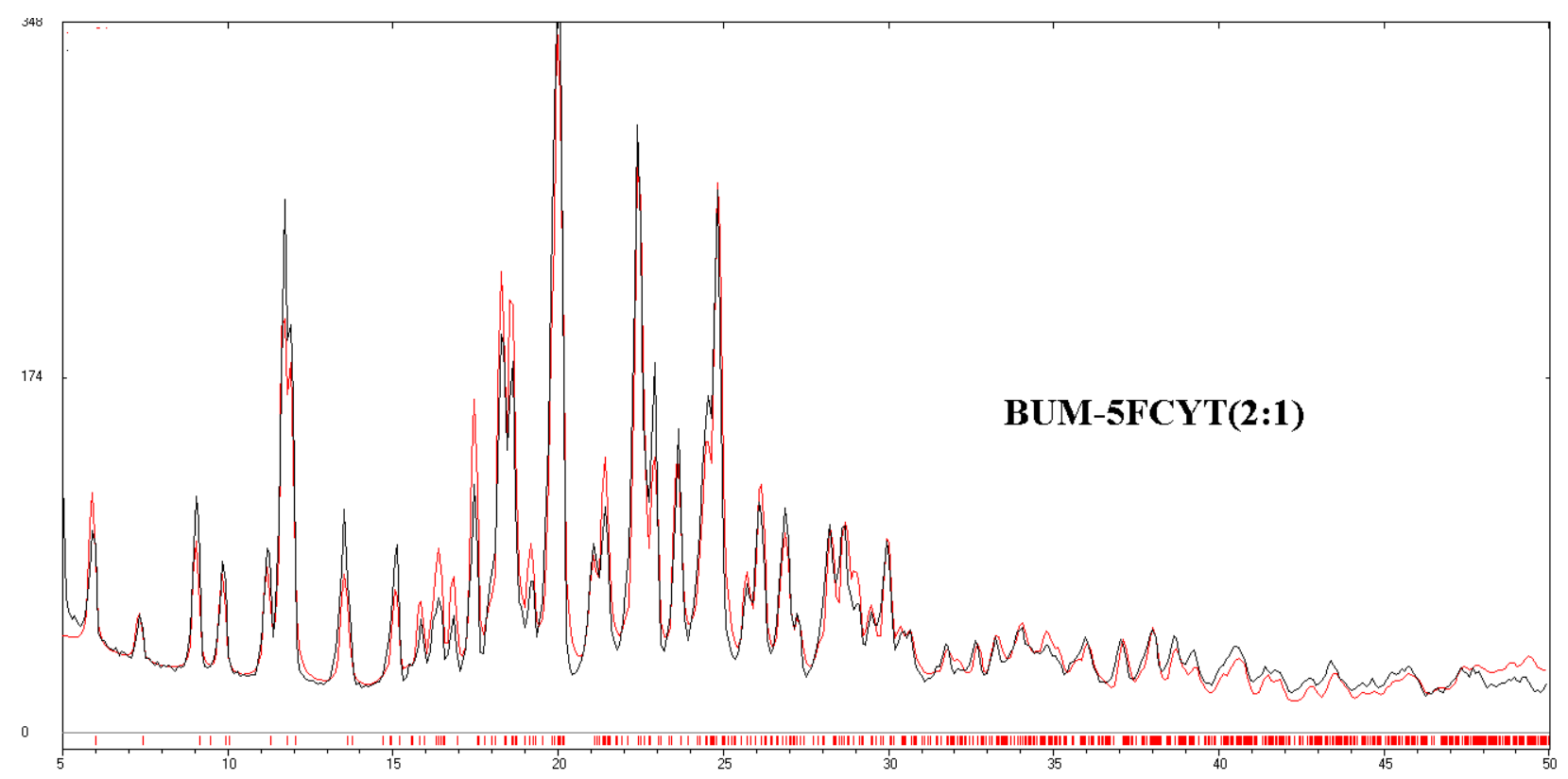

Figure S39: PXRD of BUM-5FCYT(2:1) at the end of equilibrium solubility/ phase stability experiment ( $24 \mathrm{~h}$ black) in $\mathrm{pH} 7.0$ buffer medium its matches with the calculated PXRD pattern of BUM-5FCYT (2:1) (red) of starting material indicating phase stability. 


\section{After dissolution measurement PXRD of the residue}

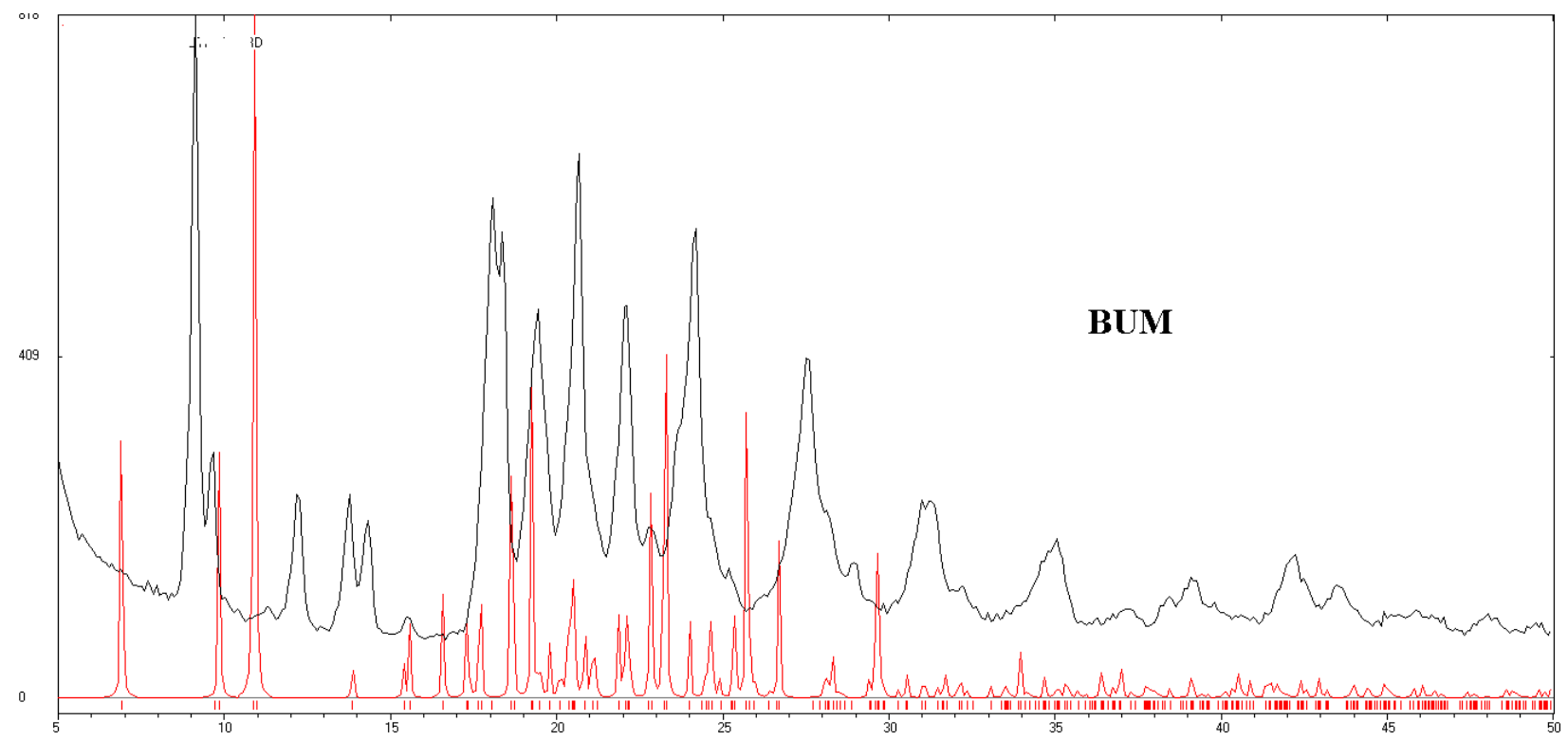

Figure S40: PXRD of BUM at the end of dissolution experiment in $\mathrm{pH} 7.0$ buffer ( $8 \mathrm{~h}$ black) does not matches with the calculated PXRD pattern of BUM (red) starting material of two phases. Hence the commercially available BUM converts to the stable BUM form.

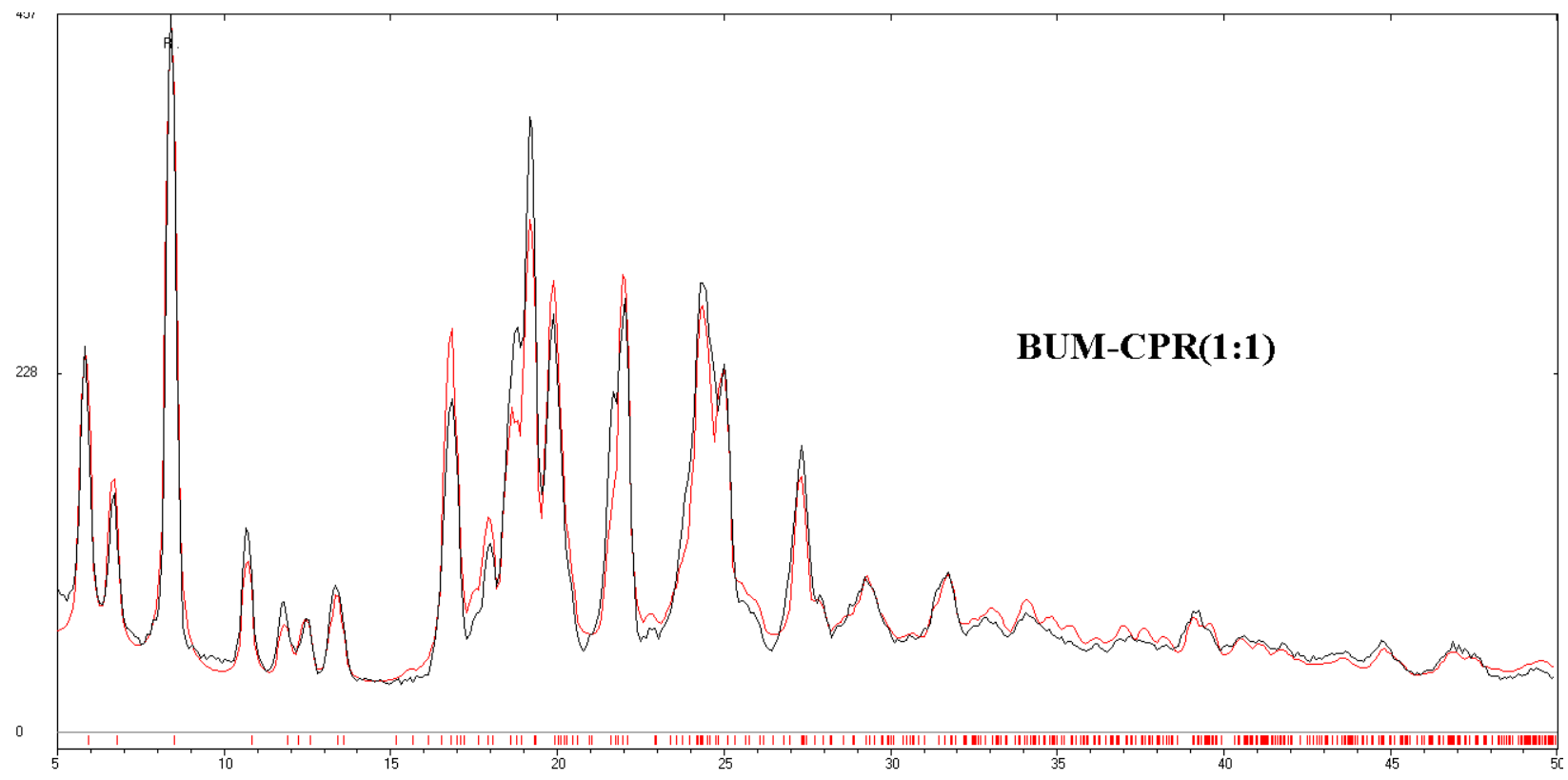

Figure S41: PXRD of BUM-CPR (1:1) at the end of dissolution experiment in pH 7.0 buffer (8 $\mathrm{h}$ black) matches with the calculated XRD pattern of BUM-CPR (1:1) (red) indicating phase stability. 


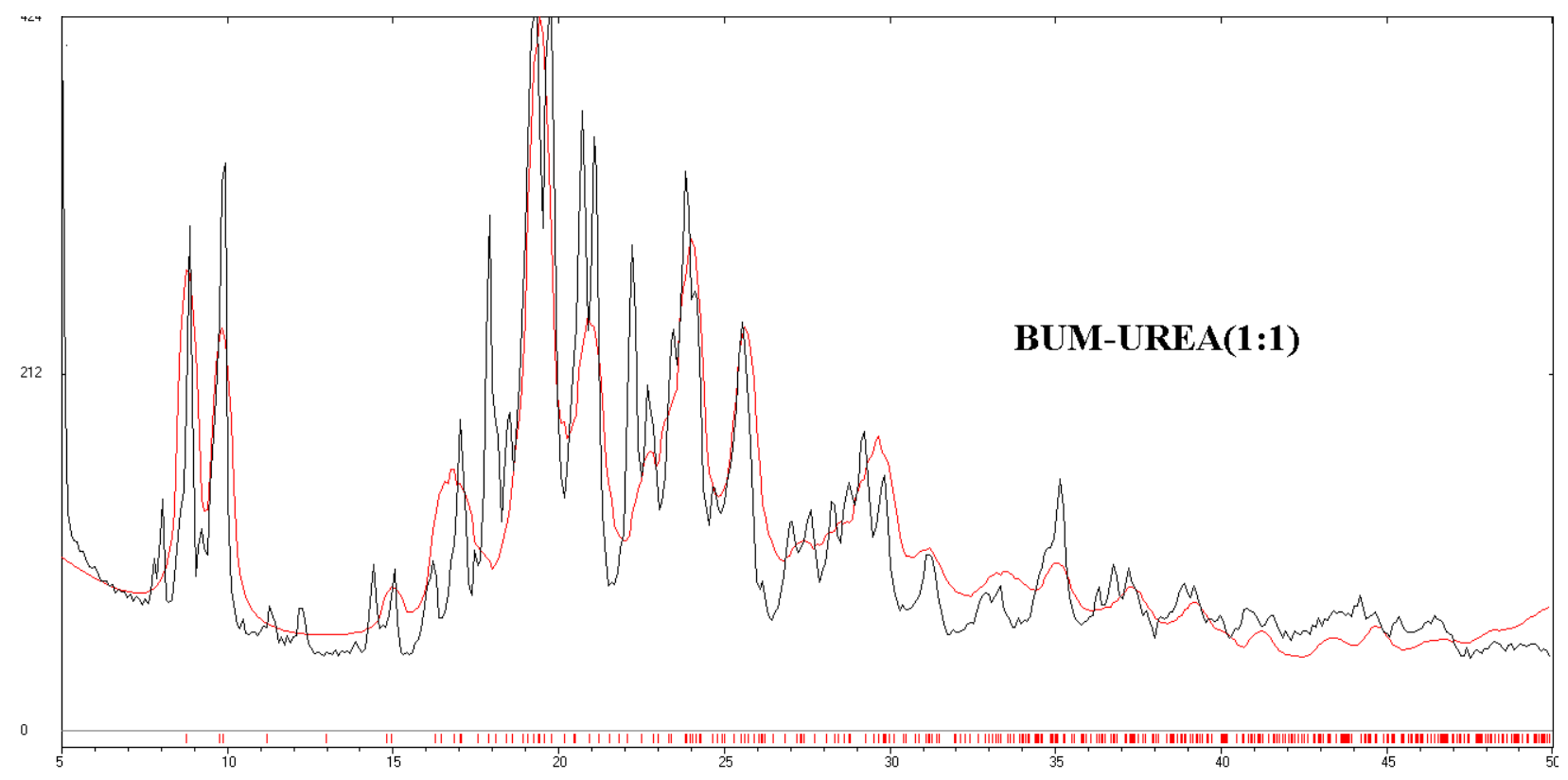

Figure S42: PXRD of BUM-UREA (1:1) at the end of dissolution experiment in pH 7.0 buffer $(8 \mathrm{~h}$ black) matches with the calculated XRD pattern of BUM-UREA (1:1) (red) indicating phase stability.

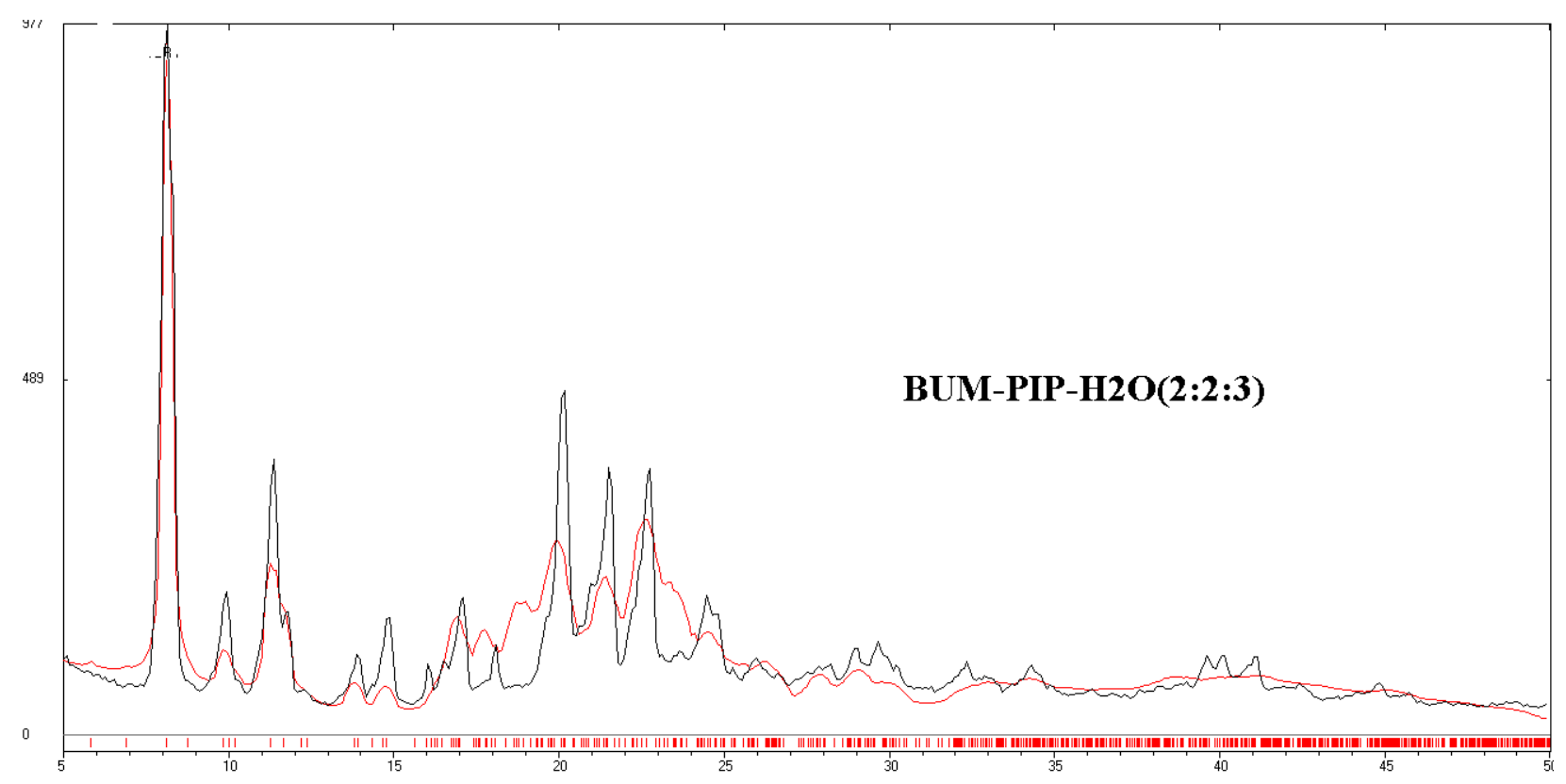

Figure S43: PXRD of BUM-PIP-H2O (2:2:3) at the end of dissolution experiment in $\mathrm{pH} 7.0$ buffer $\left(8 \mathrm{~h}\right.$ black) matches with the calculated XRD pattern of BUM-PIP- $\mathrm{H}_{2} \mathrm{O}(2: 2: 3)$ (red) indicating phase stability. 


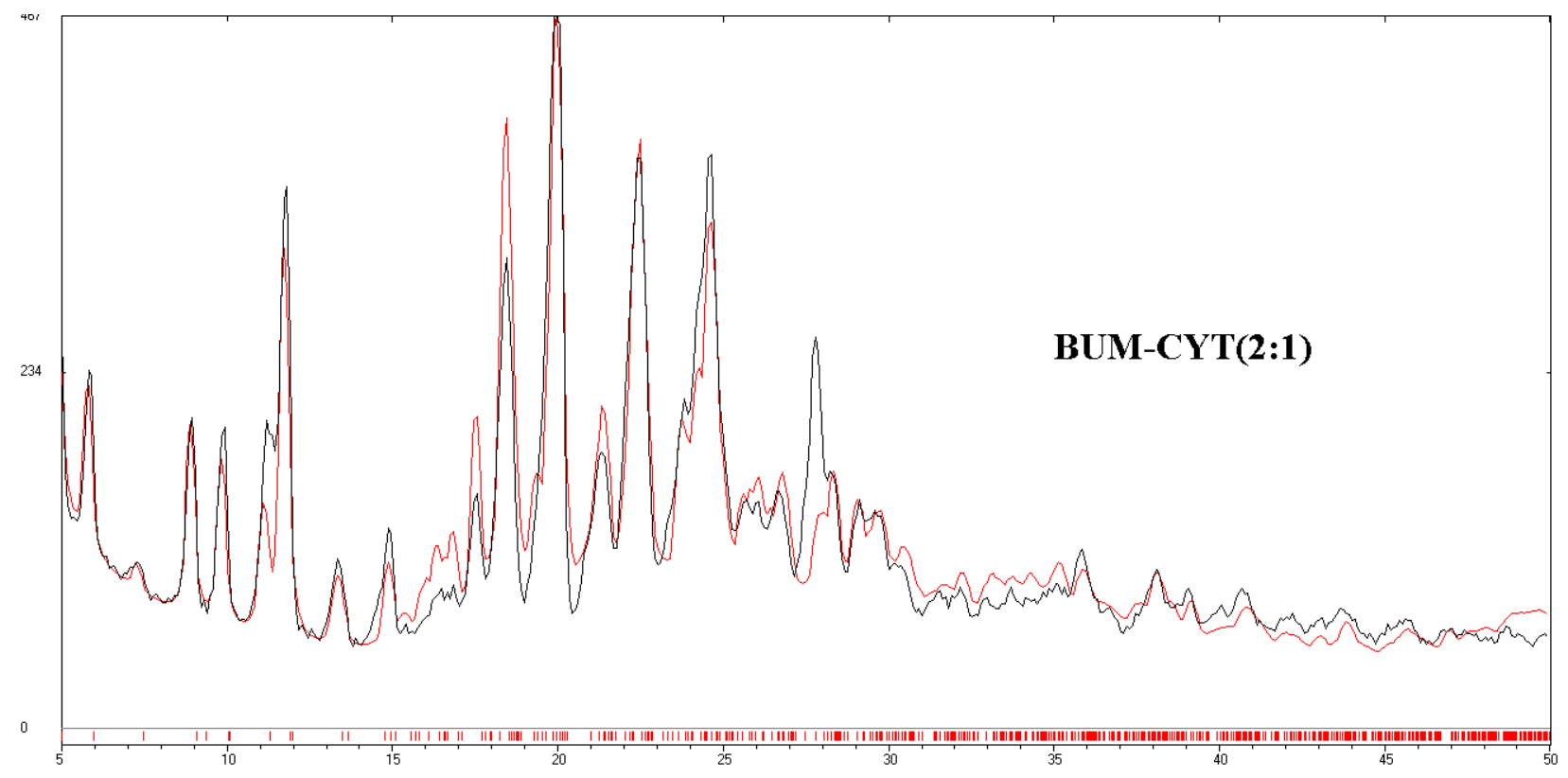

Figure S44: PXRD of BUM-CYT (2:1) at the end of dissolution experiment in $\mathrm{pH} 7.0$ buffer (8 $\mathrm{h}$ black) matches with the calculated XRD pattern of BUM-CYT (2:1) (red) indicating phase stability.

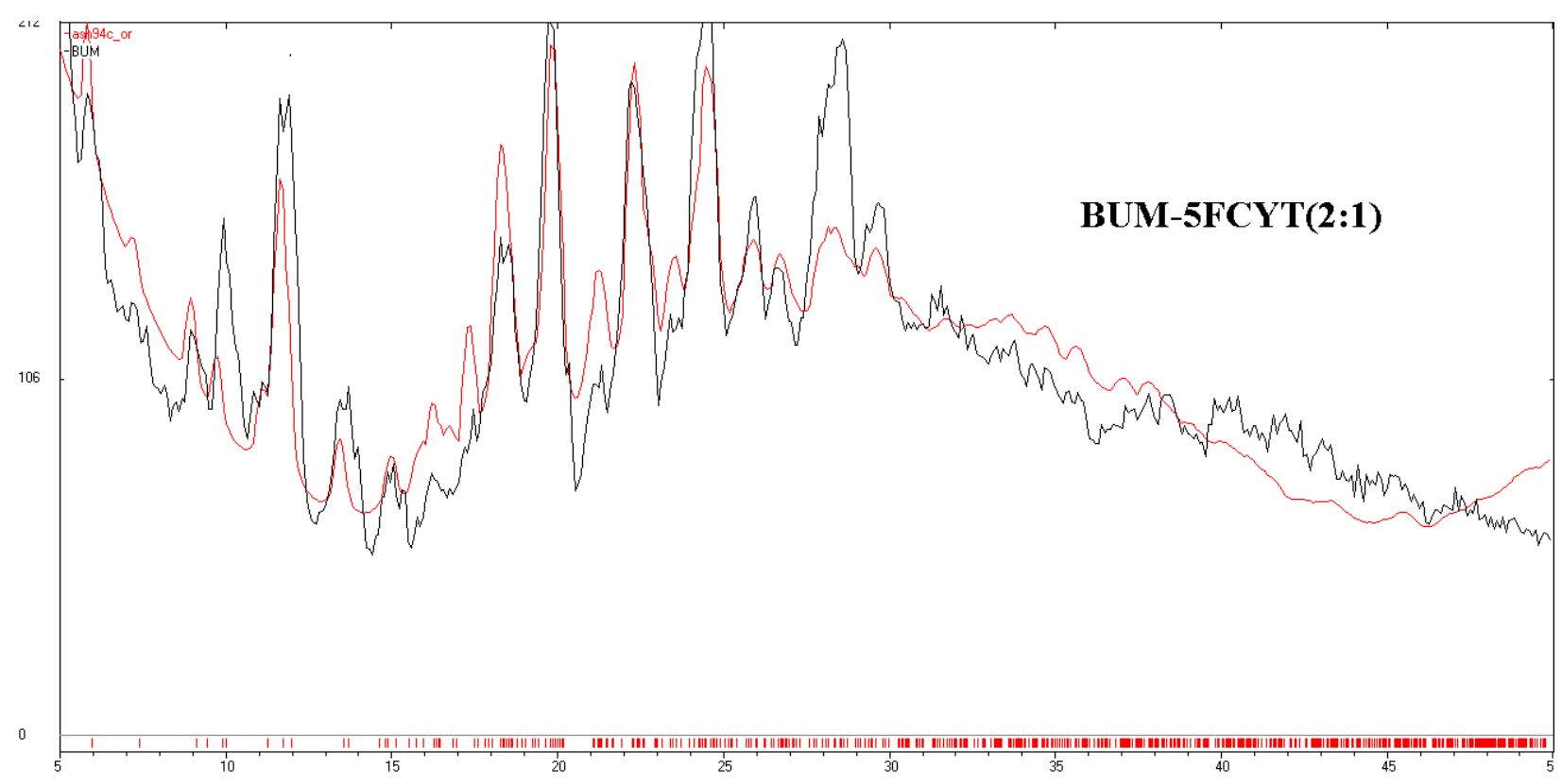

Figure S45: PXRD of BUM-5FCYT (2:1) at the end of dissolution experiment in $\mathrm{pH} 7.0$ buffer ( $8 \mathrm{~h}$ black) matches with the calculated XRD pattern of BUM-5FCYT (2:1) (red) indicating phase stability. 
Table S3: ORTEP Diagrams of BUM and its cocrystal/salts and salt-corcystals.

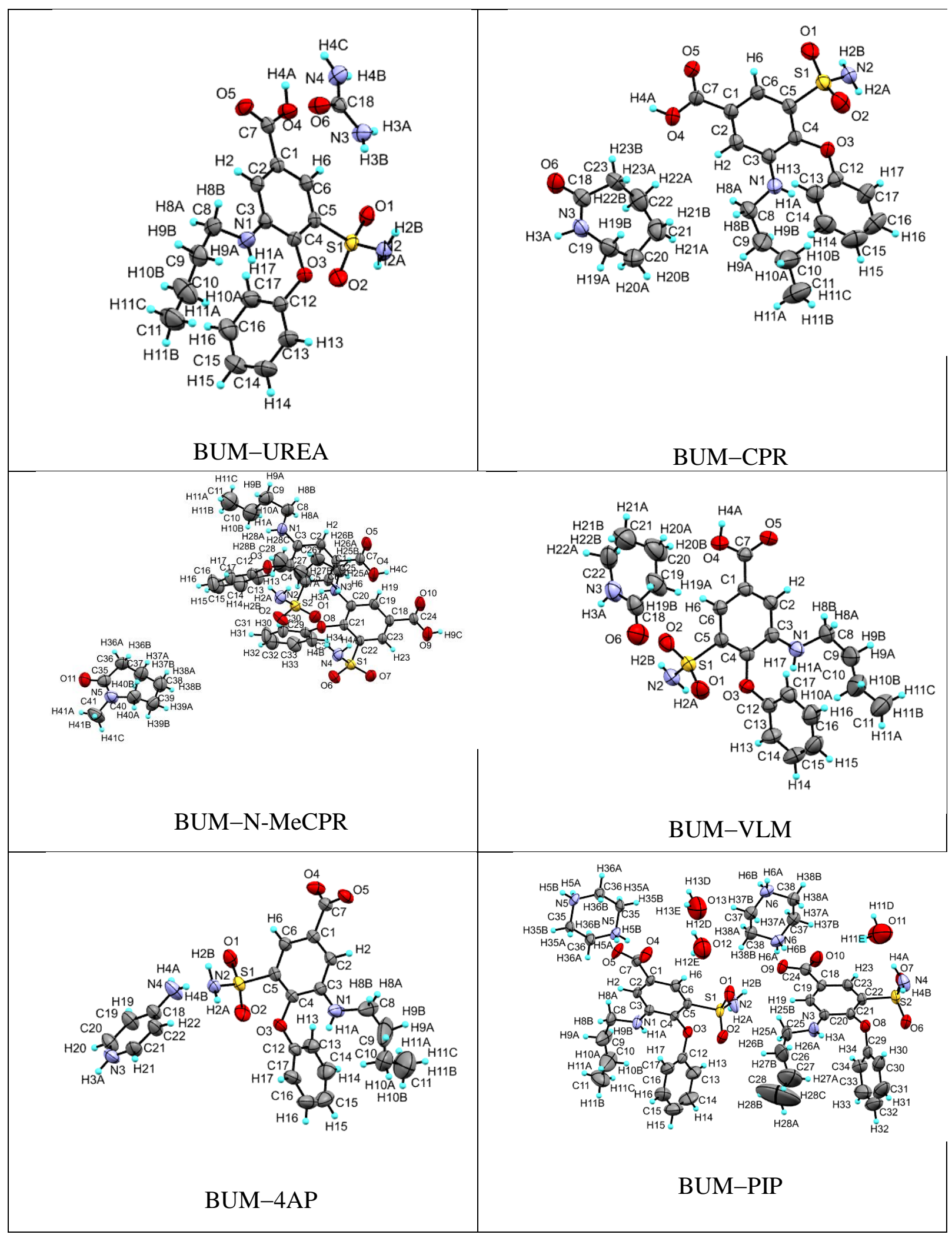



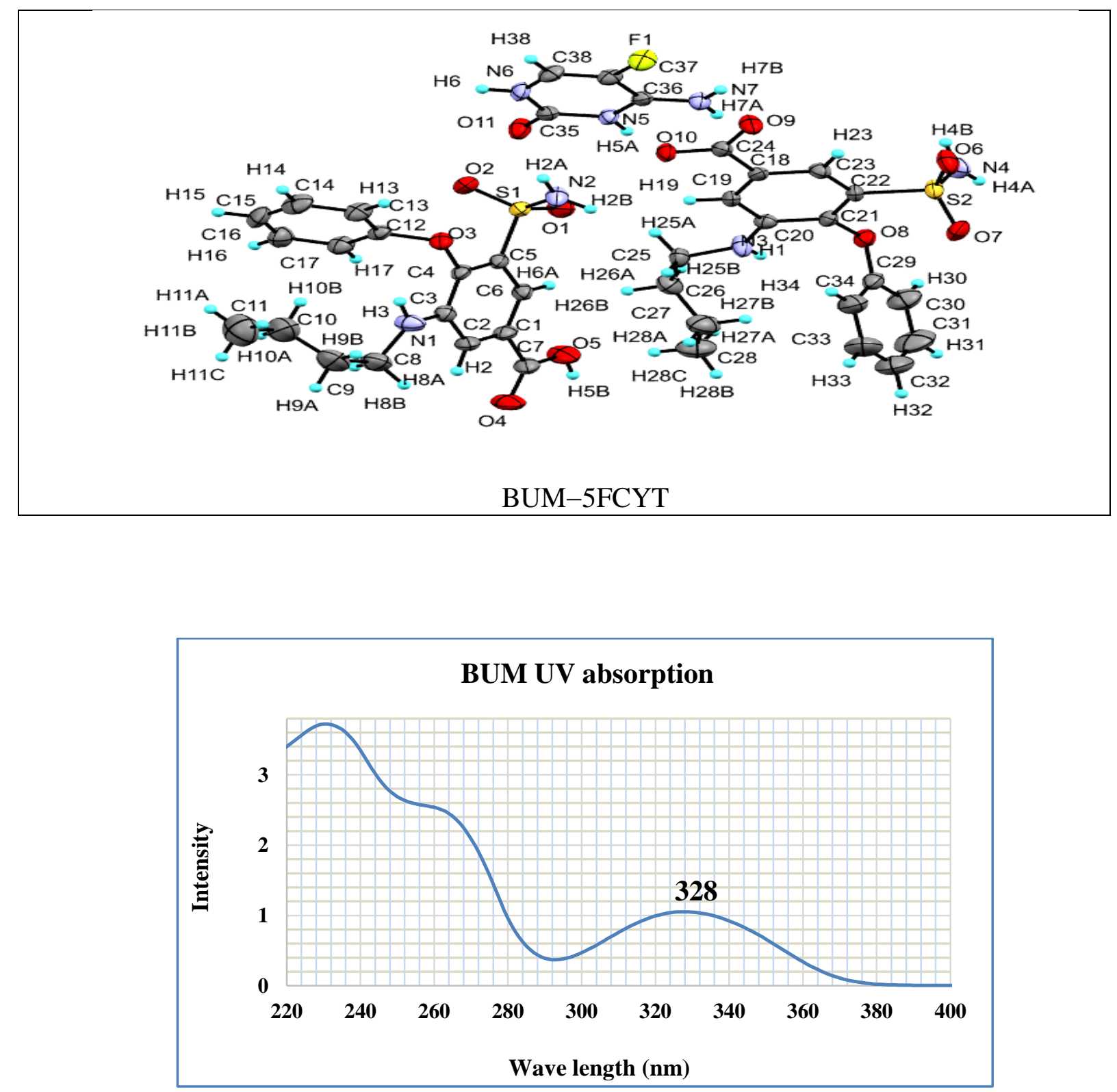

Figure S46: UV absorption of the BUM.

Table S4: Results of unsuccessful crystallization for BUM with functionalized benzoic acids.

\begin{tabular}{|l|l|}
\hline Crystallization experiment & Stoichiometry attempted (drug : coformer) \\
\hline BUM-4-hydroxy benzoic acid & $(1: 1),(1: 2)$ and $(2: 1)$ \\
\hline BUM-2,3-dihydroxy benzoic acid & $(1: 1),(1: 2)$ and $(2: 1)$ \\
\hline BUM-2,4-dihydroxy benzoic acid & $(1: 1),(1: 2)$ and $(2: 1)$ \\
\hline BUM-2,5-dihydroxy benzoic acid & $(1: 1),(1: 2)$ and $(2: 1)$ \\
\hline BUM-2,6-dihydroxy benzoic acid & $(1: 1),(1: 2)$ and $(2: 1)$ \\
\hline BUM-3,4-dihydroxy benzoic acid & $(1: 1),(1: 2)$ and $(2: 1)$ \\
\hline BUM-3,5-dihydroxy benzoic acid & $(1: 1),(1: 2)$ and $(2: 1)$ \\
\hline
\end{tabular}

